Discussion Papers of the

Max Planck Institute for

Research on Collective Goods

2020/30

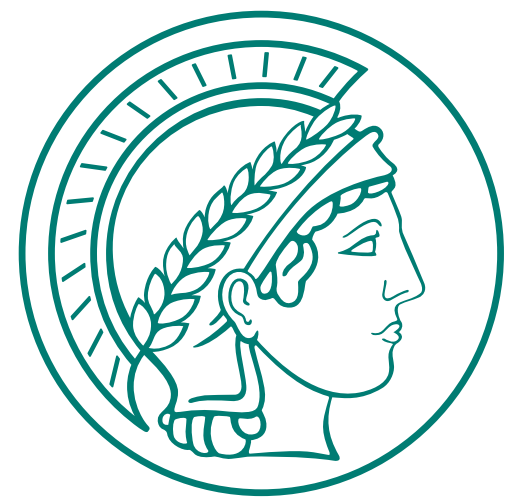

The Intrinsic Value of Decision Rights: A Note on Team vs Individual Decision-Making

Justin Buffat Matthias Praxmarer

Matthias Sutter 


\title{
The Intrinsic Value of Decision Rights: A Note on Team vs Individual Decision-Making
}

\author{
Justin Buffat / Matthias Praxmarer / Matthias Sutter
}

December 2020 


\title{
The Intrinsic Value of Decision Rights: A Note on Team vs INDIVIDUAL DECISION-MAKING*
}

\author{
Justin Buffat Matthias Praxmarer Matthias Sutter
}

\begin{abstract}
Team decision-making prevails in modern organizations. Teams often need to decide whether to delegate or make a decision themselves. Recent work has found that many individuals assign a significantly positive intrinsic value to having a decision right, which may distort the choice between delegating a decision or not. Here we examine experimentally whether teams are also prone to such distortions. While in the aggregate we find no differences between individuals and teams, we uncover an important heterogeneity within teams. Teams with a smooth decision making process have much lower intrinsic values of decision rights than individuals, often not even significantly different from zero. Yet, teams with conflicts in reaching a decision have very high intrinsic values of decision rights, thus distorting decisions. Hence, the team decision making process is of significant importance for the decision-making quality in organizations.
\end{abstract}

JEL CODES: C92, D23, D80,

Key words: Decision rights, intrinsic value, team decision making, experiment.

This version: December 12, 2020

\footnotetext{
*We are grateful for helpful comments by Björn Bartling, Stefania Bortolotti, Tim Cason, Ernst Fehr, Nobuyuki Hanaki, Holger Herz, Qiang Fu and valuable comments from audiences at the MPI in Munich, 68 degree conference at the Lofoten (FAIR), IMEBESS Florence, and seminar participants at the University of Cologne. Financial support from the University of Cologne is gratefully acknowledged. We also acknowledge Björn Bartling and Holger Herz for providing the original German instructions.

Buffat: University of Lausanne, Dept. of Organizational Behavior, Quartier UNIL-Dorigny, 1004 Lausanne, Switzerland. Praxmarer: Max-Planck-Institute for Research on Collective Goods, Kurt-Schumacher-Straße 10, D-53113 Bonn, Germany; Sutter (Corresponding author): Max-Planck-Institute for Research on Collective Goods, KurtSchumacher-Straße 10, D-53113 Bonn, Germany; University of Cologne, Department of Economics, Albertus Magnus Platz, 50923 Köln, Germany, and University of Innsbruck, Dept. of Public Finance, Universitätsstraße 15, 6020 Innsbruck, Austria
} 


\section{Introduction}

The analysis of decision making is at the core of economics and management science as decisions determine outcomes. An aspect of this that has received less attention is the importance of holding decision rights. Such decision rights may be used to make a decision oneself (as a principal), but also to delegate the decision to someone else (an agent) who may be better informed or qualified. As such, the decision right has an instrumental value as it gives control over the outcome, be it determined by an own decision or through delegation. The standard approach has assumed that there is no value to the decision right itself, but the choice between making a decision oneself or delegating it to an agent has been assumed to depend on the expected outcomes in both cases (see e.g., Grossman and Hart, 1986; Hart and Moore, 1990). While related research has also shown that non-pecuniary motives may play a role in delegating a decision or not (e.g., due to reluctance to trust or give up control, or because of regret aversion; see Bohnet and Zeckhauser, 2004; Bohnet et al., 2008; Fehr et al., 2013; Owens et al., 2014; Neri and Rommeswinkel. 2017), only the seminal work of Bartling et al. (2014) has been able to disentangle the intrinsic value of decision rights from the instrumental value, and to measure it accordingly. A positive intrinsic value means that decision makers assign a positive weight to holding the decision making right and thus the power to choose among alternatives. Bartling et al. (2014) have found significantly positive intrinsic values, and this has been confirmed in subsequent work (Ferreira et al. 2020).

From an organizational point of view, the fact that decision rights may carry a positive intrinsic value constitutes a potential source of inefficiencies. In fact, an organization mostly cares about the final outcome of a decision and should not be concerned with whether individuals attach a value to the right of making a decision - whoever ultimately makes it. Moreover, the more weight individuals put on the decision rights per se, the larger the potential inefficiencies, as a positive intrinsic value may drive a wedge between the choice to make a decision oneself or to delegate it to an agent (which may be more efficient if agents have lower decision costs or better information). Hence, the intrinsic value of decision rights may actually distort decisions within organizations. While one study shows that top-tier decision makers in organizations do not always behave rationally in delegating financial decisions (Graham et al. 2015), evidence on whether teams are better or worse than individuals in choosing optimally on delegating a decision or not is scant. Obtaining such evidence is of crucial importance, however, given that the empowerment of teams within organizations is on the fast track and more and more decisions within organizations are made by teams (Lazear and Shaw, 2007, Bandiera et al., 2013).

The literature on team decision making (see reviews by Charness and Sutter, 2012, Kugler et al., 2012; Kocher et al., 2020) has found considerable evidence that teams are closer to the standard textbook decision maker that cares only about outcomes, but much less - if at all - about procedures (or prosocial concerns). As such, teams seem to be "more rational" and "less behavioral" decision makers (see e.g. Cooper and Kagel, 2005; Maciejovsky et al., 2013. Keck et al. 2014). Seen from this angle, it might be wise of organizations to implement team 
decision making as it may put more weight on the instrumental value of decision rights - thus caring predominantly about outcomes - and limit the degree to which decision makers care about the right to make decisions per se. Yet, so far there is no evidence available whether this is the case or not - and this lack is not the least due to the fact that measuring the intrinsic value of decision rights has been a challenging task for long and has only recently been successfully implemented.

In this paper, we use the method developed by Bartling et al. (2014) to measure the intrinsic value of decision rights and examine whether there is a difference between individuals and teams in this respect. If so, this would provide a strong rationale for organizations to rely more and more on team decision making.

Based on an experiment with 210 participants, either in the role of individual decision makers or teams, we find the following results. First, in the aggregate there are no differences between individuals and teams in the intrinsic value that they attach to decision rights, and the intrinsic value is significantly positive. It is remarkable that the magnitude of the intrinsic value that we observe matches the original results of Bartling et al. (2014) very accurately. In fact, we find not a single significant difference between our treatment with individual decision makers and the experiment (with individuals) of Bartling et al. (2014).

Second, our first result masks an important heterogeneity in teams that is intimately related to the team decision making process. In our treatment with teams, two subjects were paired with each other and had to reach a joint decision whether or not to delegate a decision to an agent or make an own choice as principal. Team members could communicate with each other through a real-time chat. We observe two types of teams. Based on a post-experimental questionnaire and on an analysis of the communication process during the experiment, we can identify one set of teams with relatively frequent communication and successful coordination on a joint decision. We call this set the "smooth teams" in the following. There is also a second set of teams labelled "conflict teams" henceforth. They are characterized by less communication among team members, less agreement, and a higher level of dissatisfaction with the team decision making process.

We find that smooth teams display a significantly lower intrinsic value of decision rights than individuals, and in many cases their intrinsic value is not even significantly different from zero. The latter implies that smooth teams often only care about the instrumental value of decision rights, and put zero weight on the intrinsic value. Yet, this is only true if both team members are satisfied with the team decision making process and communicate well with each other - as organizations would wish it to be. Our set of conflict teams, however, is markedly different. Their intrinsic value of decision rights is about twice as large as for individuals, and about five times the magnitude of smooth teams. This indicates that when the team decision making process is dissatisfactory, the intrinsic values of decision rights balloon and distort the choices whether or not to delegate a decision to another party. Pooling both types of teams makes their average intrinsic value of decision rights look as if they were indistinguishable from individuals' valuations of decision rights. Behind this aggregate null-result lies an important 
insight for organizations, however, as the smoothness of the decision making process is very closely related to how teams balance instrumental and intrinsic values of decision rights. 1

The rest of the paper is organized as follows. Section 2 introduces the experimental design and procedure. Section 3 presents our results, and section 4 concludes.

\section{Experimental Design}

We use the experimental design developed by Bartling, Fehr, and Herz (2014, hereafter BFH) to elicit and measure the intrinsic value of decision rights. As noted by $\mathrm{BFH}$, the main difficulty in measuring the intrinsic value of decision rights is to separate it from the instrumental value. To achieve this goal, BFH have used two parts - a principal-agent part and a lottery part. Their design allows measuring the value (in percent) that subjects attach to being in control of a decision rather than delegating it. In a nutshell, the intuition is the following. The first (principal-agent) part serves to elicit subjects' preferences over the delegation of a decision right. The second (lottery) part uses the data from the first part to elicit subjects' certainty equivalents for lotteries that have identical payoff consequences as when making an own decision, respectively delegating it, in the first part. The lottery part has no delegation opportunity, and therefore a comparison of both parts allows quantifying the intrinsic value of decision rights. In the following, we describe the setup developed by $\mathrm{BFH}$ in more detail and then present our procedures and treatments.

\subsection{Measuring the intrinsic value of decision rights}

\subsubsection{The principal-agent part}

The first part of the experiment consists of a principal-agent delegation game in which the principal $P$ initially owns the decision right, but can delegate it to an agent $A$. Both the principal and the agent make two decisions in case they own the decision right in the end: (i) They choose one of two project alternatives ( $\mathcal{P}$ or $\mathcal{A}$ ) and (ii) they select a costly effort level that determines the probability of success of the chosen project. An effort level $e^{i} \in[0,100]$, with $i=P, A$, indicates (in percent) the probability of the project being successful, with the counter-probability yielding an outside option for both the principal and the agent. Only the party which finally holds the decision right has to pay the cost of the chosen effort level, with $c(e)=k e^{2}$ and $k>0$.

The principal, who initially holds the decision right, has to make a third decision: (iii) she selects a minimum requirement for the agent's effort, denoted $\underline{e}$. This design feature is crucial in BFH's design. Delegation takes place if and only if the agent's chosen effort is at least as high as the minimum required by the principal, i.e., $e^{A} \geq \underline{e}$. This mechanism ensures that the principal keeps the decision right whenever the agent's chosen effort would make her worse off and delegates the right otherwise. Therefore, it is in the principal's best interest to set the

\footnotetext{
${ }^{1}$ One reason for conflicts within teams might be that team members are dissatisfied with the procedures for team decision making; see, e.g., Bolton et al. (2005); Chlaß et al. (2019); Dold and Khadjavi (2017). Here, we are not interested in the role of (un)fair procedures.
} 
minimum requirement in a way that if the chosen effort of the agent is equal to the minimum requirement, the principal is indifferent between keeping and delegating the decision right.

Note that by design, holding the decision right induces a trade-off: On the one hand, the party with the decision rights has her decisions implemented, and this is important because the principal always weakly prefers project $\mathcal{P}$ over $\mathcal{A}$, and the agent $\mathcal{A}$ over $\mathcal{P}$. On the other hand, the party with the decision rights has to bear the cost of the effort that determines the likelihood of the project's success.

Table 1 shows the payoffs associated with the two different projects in the 10 games played in the principal-agent part. These games reflect different stake sizes and different payoff allocations between the principal and the agent $2^{2}$ The following example illustrates the decisions and payoff consequences of the principal-agent part:

A numerical example. Suppose that in Game 3 of Table 1 the principal chooses an effort $e^{P}=60$ (with effort costs of 36), a minimum effort requirement $\underline{e}=40$ (costs of 16 ) and project alternative $\theta^{P}=\mathcal{P}$.

Assume the agent chooses effort $e^{A}<40$ : The decision right remains with the principal and alternative $\mathcal{P}$ is implemented. Thus, with $60 \%$ probability (because of $e^{P}=60$ ) the principal earns the earnings from the successful project $\mathcal{P}$ minus the effort costs, i.e., $180-36=144$, and the agent 140 , while with $40 \%$ probability the principal gets $100-36=64$ and the agent 100 .

Assume $e^{A}=60$ and thus $e^{A} \geq \underline{e}$ : The decision right is delegated to the agent. Hence, with $60 \%$ probability (because of $e^{A}=60$ ) the principal gets 140 and the agent $180-36=144$, while with $40 \%$ probability the principal earns 100 and the agent $100-36=64$.

${ }^{2}$ In Appendix A.3 and Figure S2 we show that our main results are independent of the stake sizes. 
Table 1: Parameters of the delegation games

\begin{tabular}{|c|c|c|c|c|c|c|c|c|c|}
\hline & \multicolumn{4}{|c|}{ Project Successful } & \multirow{2}{*}{\multicolumn{2}{|c|}{$\frac{\text { Project Unsuccessful }}{\text { Outside option }}$}} & \multirow{3}{*}{$\begin{array}{l}\frac{\text { Stake size }}{\text { HS - high, }} \\
\text { LS - low }\end{array}$} & \multirow{3}{*}{$\begin{array}{c}\text { Cost parameter }(k) \\
k=0.01-\text { low }, \\
k=0.02-\text { high }\end{array}$} & \multirow{3}{*}{$\begin{array}{c}\text { Optimal effort }\left(e^{*}\right) \\
\text { Principal } \\
\text { effort }\left(e^{P}\right)\end{array}$} \\
\hline & \multicolumn{2}{|c|}{ Alternative $\mathcal{P}$} & \multicolumn{2}{|c|}{ Alternative $\mathcal{A}$} & & & & & \\
\hline & $\begin{array}{c}\text { Principal } \\
P_{\mathcal{P}}\end{array}$ & $\begin{array}{c}\text { Agent } \\
A_{\mathcal{P}}\end{array}$ & $\begin{array}{c}\text { Principal } \\
P_{\mathcal{A}}\end{array}$ & $\begin{array}{c}\text { Agent } \\
A_{\mathcal{A}}\end{array}$ & $\begin{array}{c}\text { Principal } \\
P_{0}\end{array}$ & $\begin{array}{c}\text { Agent } \\
A_{0}\end{array}$ & & & \\
\hline Game 1 & 220 & 190 & 190 & 220 & 100 & 100 & LS & 0.01 & 60 \\
\hline Game 2 & 280 & 235 & 235 & 280 & 100 & 100 & LS & 0.01 & 90 \\
\hline Game 3 & 180 & 140 & 140 & 180 & 100 & 100 & LS & 0.01 & 40 \\
\hline Game 4 & 220 & 160 & 160 & 220 & 100 & 100 & LS & 0.01 & 60 \\
\hline Game 5 & 260 & 260 & 260 & 260 & 100 & 100 & LS & 0.01 & 80 \\
\hline Game 6 & 440 & 380 & 380 & 440 & 200 & 200 & HS & 0.02 & 60 \\
\hline Game 7 & 560 & 470 & 470 & 560 & 200 & 200 & HS & 0.02 & 90 \\
\hline Game 8 & 360 & 280 & 280 & 360 & 200 & 200 & HS & 0.02 & 40 \\
\hline Game 9 & 440 & 320 & 320 & 440 & 200 & 200 & HS & 0.02 & 60 \\
\hline Game 10 & 520 & 520 & 520 & 520 & 200 & 200 & HS & 0.02 & 80 \\
\hline
\end{tabular}

Notes: The table provides the payoffs for principals and agents in 10 different games depending on whether the project is successful or unsuccessful. The table also indicates "LS" for low-stake games (Games 1-5) and "HS" for high-stake games (Games 6-10), the cost parameters, and the optimal effort choice $\left(e^{*}\right)$ of a risk-neutral and selfish principal without any intrinsic valuation of a decision right.

\subsubsection{The lottery part}

The purpose of the lottery part is to present the principals with payoff consequences that are equivalent to the principal-agent part, but that take place outside of the delegation context.

Specifically, in this part the principal is presented with two lotteries: a "control" lottery and a "delegation" lottery. Although these lotteries reflect decisions from the first part (as explained below), they are exogenously given to the principal in this part. The task of the decision maker is to state her certainty equivalents for each of the lotteries. The difference in certainty equivalents between the control lottery and the delegation lottery will then be used as a measure of the intrinsic value of the decision rights.

Control lotteries represent payoffs and probabilities when the principal keeps the decision rights, i.e., retains control. They are hence solely determined by the principal's choices regarding the project alternative and the probability of success. Let $L^{c}\left(e^{P}, \theta^{P}\right)$ denote the control lottery, with $\theta^{P}$ the project alternative chosen by the principal and $e^{P}$ the chosen probability of success (from the principal-agent part). The delegation lottery represents payoffs and probabilities when the principal delegates the decision to the agent. Let $L^{d}\left(e^{A}, \theta^{A}\right)$ denote the delegation lottery when the agent chooses effort $e^{A} \geq \underline{e}$ and project alternative $\theta^{A}$. The worst delegation lottery for the principal is constructed when the agent chooses her preferred alternative $\mathcal{A}$ and selects the lowest effort such that delegation takes place, i.e. $e^{A}=\underline{e}$. This worst delegation lottery is denoted $L^{\underline{d}}(\underline{e}, \mathcal{A})$.

Subjects report their certainty equivalent for each lottery, $C E\left(L^{c}\right)$ for the control and 
$C E\left(L^{\underline{d}}\right)$ for the delegation lottery.

Continuation of the numerical example. Using the previous assumptions, the control lottery yields payoffs 144 to the principal and 140 to the agent with probability 0.6 , and 64 to the principal and 100 to the agent with probability 0.4. The delegation lottery yields 140 to the principal and $164(=180-16)$ to the agent with a probability of 0.4 , and 100 to the principal and $84(=100-16)$ to the agent with a probability of 0.6 .

Measuring the intrinsic value. Next, we follow BFH and show how the intrinsic value of the decision rights can be obtained from comparing the utilities of both lotteries. Let's start with the case of a principal who puts zero value on the decision right per se. If the principal plays a lottery, her expected utility is given by the consequences of the lottery she faces, $U\left(L^{c}\right)$ for the control lottery and $U\left(L^{\underline{d}}\right)$ for the delegation lottery. If the principal does not play the lottery she receives her stated certainty equivalent $C E(L)$ and the agent receives the outside option $\mathcal{A}_{0}$, so that the principal's utility is $u\left(C E(L), \mathcal{A}_{0}\right) 3^{3}$

It is optimal for a principal to choose a minimum effort requirement $\underline{e}^{*}$ so that the utilities are equal, i.e.,

$$
U\left(L^{c}\right)=U\left(L^{\underline{d}}\right) \Leftrightarrow u\left(C E\left(L^{c}\right), \mathcal{A}_{0}\right)=u\left(C E\left(L^{\underline{d}}\right), \mathcal{A}_{0}\right)
$$

For the latter equation to hold, the certainty equivalents must be equal, $C E\left(L^{c}\right)=$ $C E\left(L^{\underline{d}}\right)$. Hence, without any intrinsic valuation of decision rights, the gap in certainty equivalents is zero.

Now suppose that the principal intrinsically values decision rights per se. Her utility directly depends on the allocation of the decision rights. The expected utility of a lottery is then described as $U\left(L^{w}, w\right)$ with $w=\{c, d\}$ indicating either keeping control over the decision $(w=c)$ or delegating it $(w=d)$. Expression 1 is modified accordingly:

$$
U\left(L^{c}, c\right)=U\left(L^{\underline{d}}, d\right) \Leftrightarrow u\left(C E\left(L^{c}\right)+V_{c}, \mathcal{A}_{0}\right)=u\left(C E\left(L^{\underline{d}}\right)+V_{\underline{d}}, \mathcal{A}_{0}\right),
$$

where $V_{c}$ and $V_{d}$ respectively capture the potential intrinsic values of being in control and of delegating. For equation (2) to hold, it must be that

$$
V_{c}-V_{\underline{d}}=C E\left(L^{\underline{d}}\right)-C E\left(L^{c}\right) \equiv I V,
$$

where we define $I V$, the intrinsic value, as the difference in certainty equivalents. If $V_{c}>V_{\underline{d}}$, the value placed on being in control outweighs the value of delegating and $I V=C E\left(L^{\underline{d}}\right)-C E\left(L^{c}\right)>$ 0 . Hence, a positive difference in certainty equivalents indicates a positive intrinsic value of decision rights.

${ }^{3}$ The agent receives the outside option to match what the agent would receive in the delegation game when the project is not successful. 
In the results section, we will normalize the intrinsic value IV by the certainty equivalent of the control lottery, i.e.,

$$
I V \%=\frac{C E\left(L^{\underline{d}}\right)-C E\left(L^{c}\right)}{C E\left(L^{c}\right)} .
$$

This measure indicates the percentage with which the principal values the delegation lottery over the control lottery. Moreover, this measure ensures that values of games with different stakes, hence different certainty equivalents, can be compared to each other.

\subsection{Procedure}

In the instructions, principals and agents were neutrally referred to as Role A and Role B, respectively. In the first part, principals (Role A) and agents (Role B) played each of the 10 delegation games (see Table 1 in a random order ${ }_{4}^{4}$ We implemented a perfect stranger matching such that each principal was paired with another agent only once (and vice versa).

In the second part, both roles faced a control lottery and a delegation lottery for each of the 10 decisions from the first part, thus yielding a total of 20 (randomly ordered) decisions in this part. Matching of a decision maker in role A with one in role B was random for each decision. For each lottery, we elicited the certainty equivalent in an incentive compatible way following Becker et al. (1964). In particular, a decision maker had to specify the smallest certain payoff she would accept - the certainty equivalent - instead of playing the offered lottery. The computer then randomly drew a number from a uniform distribution 5 and the lottery was played if the decision maker's certainty equivalent was strictly larger than the randomly selected number. If the certainty equivalent was smaller than or equal to the randomly drawn number, the decision maker received the randomly drawn amount. In addition, a decision maker's choice also affected the payment of a randomly matched participant, whose payoff was determined by the outcome of the lottery should the lottery have been played or by a fixed payment otherwise (outside option of either 100 or 200, see Table1) 6

\subsection{Treatments}

We implemented two treatments, labeled SINGLE and TEAM. Treatment SINGLE is a replication of the original individual decision-making condition in Bartling et al. (2014). The treatment closely follows the steps described above and subjects were exposed to BFH's original instructions, software (of course only for SINGLE, we adapted it for TEAM) and experimental

\footnotetext{
${ }^{4}$ The order was random at the session level but the same for all principals within a given session. Agents faced a different random order.

${ }^{5}$ Note that the boundaries of the distribution were determined by the low and the high payment of the given lottery.

${ }^{6}$ We follow here BFH in exact detail, meaning that each principal was also a random passive recipient from one agent's choices. However, this was only announced (as a surprise earning) at the very end of the experiment. Agents also played the lottery part to keep them entertained in the second part. We - as well as BFH originally are, however, only interested in the principals here.
} 
procedure (for which we thank BFH) ${ }^{7}$

In treatment TEAM, a team consisted of two subjects in the role of principals (Role A), while the agent was still played by a single subject (Role B). Since we are mainly interested in the decisions of principals, we only let this role be played by a team. The pair of principals remained fixed for the entire duration of the experiment. The principals in TEAM faced the same set of decisions as the single principals in SINGLE, but teams had to reach a joint decision before moving to the next delegation game or lottery. When a new game or lottery was presented to principals, they had to enter a proposal for the team decision. That meant in the principalagent part to decide about the minimum effort requirement for the agent, the preferred project alternative, and the own effort in case the decision was taken by the principals (rather than delegated to the agent). In the lottery stage, the decision was about the certainty equivalent of a specific lottery.

In order to facilitate reaching a unanimous decision, team members could exchange messages in a free-form and real-time chat. Note that the chat could even be used before entering the first proposal for the team decision, and many teams used this option. Once a proposal had been entered, each principal could confirm at any time the decisions she had proposed. If both principals confirmed the same decisions, then they could move on to the next delegation game (in stage 1) or lottery (in stage 2). If there was still disagreement, principals could adjust their choices (typically after having discussed further on what to agree upon). Importantly, we did not impose any time limit on the principals to reach a joint decision. We did so to avoid any kind of time pressure that might interfere with potential treatment effects. ${ }^{8}$

\subsection{Post-experimental questions to classify teams}

We also collected information on how team members perceived the overall decision-making process in their team. In particular, we asked each team member (i) whether she felt excluded from the decision-making process and (ii) whether she gave up in the decision-making process at some point during the experiment. Both questions could be answered by "Yes" or "No". These two questions were motivated by previous research pointing out that besides group consensus, individual acceptance and member satisfaction are important for effective team decisions (see e.g., Priem et al., 1995). For this reason we were expecting the answers to these questions to relate to a team's decisions. More precisely, in the results section we will distinguish between two different types of teams. We will speak of "smooth teams" as those in which both members answered both questions with "No", meaning that both team members seemed to have been satisfied with the team decision making process. Contrary to that, we will

${ }^{7}$ The only difference between our SINGLE treatment and the original treatment in BFH is the wording we use to describe the different roles. While BFH refer to the principal and to the agent as Participant A and Participant B, we refer to them as Role A and Role B. We modified the wording to keep the labels identical also in treatment TEAM in which there was more than one participant in the role of a principal (Role A).

\&Carnevale and Lawler (1986) provide evidence that time pressure reduces the frequency of reaching agreements in bilateral negotiations in which bargaining parties can make offers and counter-offers. For more evidence on the effects of time pressure on individual decision making see, e.g., Spiliopoulos and Ortmann (2018) or Kocher et al. (2019). 
refer to "conflict teams" when at least one member in a team answered one or both questions with "Yes", thus indicating problems in the team decision making process. 9

\subsection{Participants and payments}

The sessions were run at the experimental laboratory of the University of Cologne (C-LER). A total of 210 participants were recruited with ORSEE (Greiner, 2015). We conducted 7 sessions with 30 participants each: 4 sessions for treatment SINGLE (60 Role A, 60 Role B) and 3 sessions for treatment TEAM (60 Role A - yielding 30 teams as principals, and 30 Role $\mathrm{B}$ ). The experiment was computerized using z-Tree (Fischbacher. 2007). Sessions lasted on average 105 minutes for subjects in treatment SINGLE and 125 minutes for subjects in treatment TEAM. To determine payments, one decision out of the ten delegation games and two decisions out of the twenty lottery decisions were randomly chosen to be payoff relevant. Participants earned on average $€ 25$ (including a $€ 4$ show-up fee) 10

At the beginning of each part, new instructions were handed out individually together with a sheet including questions that tested the understanding of the experimental instructions 11 Subjects typed in their answers to the control questions and could start the experiment only when all questions had been correctly answered.

\section{Results}

\subsection{Individual versus team decision-making}

We start by looking at the average intrinsic value - defined in equation (4) as $I V \%$ and averaged over all 10 delegation games - dependent on the treatment. Figure 1 presents the values for SINGLE, TEAM, and for the seminal study of BFH (2014). We note first that our SINGLE treatment yields very similar findings to BFH. The $I V \%$ is $16.7 \%$ in $\mathrm{BFH}$ and $17.0 \%$ in our SINGLE treatment. The two samples are statistically indistinguishable from each other (twosided t-test, $p=0.91$ ) 12 Hence, our findings in SINGLE provide an independent replication of $\mathrm{BFH}$. When we compare the intrinsic values of decision rights between our treatments, we see no difference between SINGLE (17.0\%) and TEAM (17.6\%; t-test: $p=0.90$; Mann-Whitney U-test: $p=0.51$ ). We summarize these results on the aggregate level as follows:

Result 1. In the aggregate, individuals and teams both have positive intrinsic values of decision rights and these values do not differ systematically from each other. Moreover, our individual data confirm the earlier results of Bartling, Fehr, and Herz (2014).

${ }^{9}$ Following the design of BFH, we also collected data on loss aversion and illusion of control, but do not report on these measures, as they are not correlated with the intrinsic value (as in the original study).

${ }^{10}$ The average payment also includes one decision from the loss aversion task and the money that subjects kept in the illusion of control task.

${ }^{11} \mathrm{~A}$ translated version of the instructions for SINGLE and TEAM is available in the Appendix.

${ }^{12}$ In Appendix A.1 we discuss the comparison of BFH and our treatment SINGLE in more detail by looking at single games (Figure S1. Also there we find practically no difference between both samples. 
Figure 2 looks at each delegation game separately and provides further evidence that, in the aggregate, teams do not assign significantly different values to decision rights than individuals. In all games, except for game 7 , individuals and teams do not value decision rights differently. Table S1 in the Appendix shows the OLS regressions of $I V \%$ on the dummy TEAM for each of the ten games, showing only one significant difference for game 7 . This means that our expectation of teams having lower intrinsic values - because they might care relatively more for the instrumental value - is not confirmed. For this reason, we take a closer look into what was going on in teams.

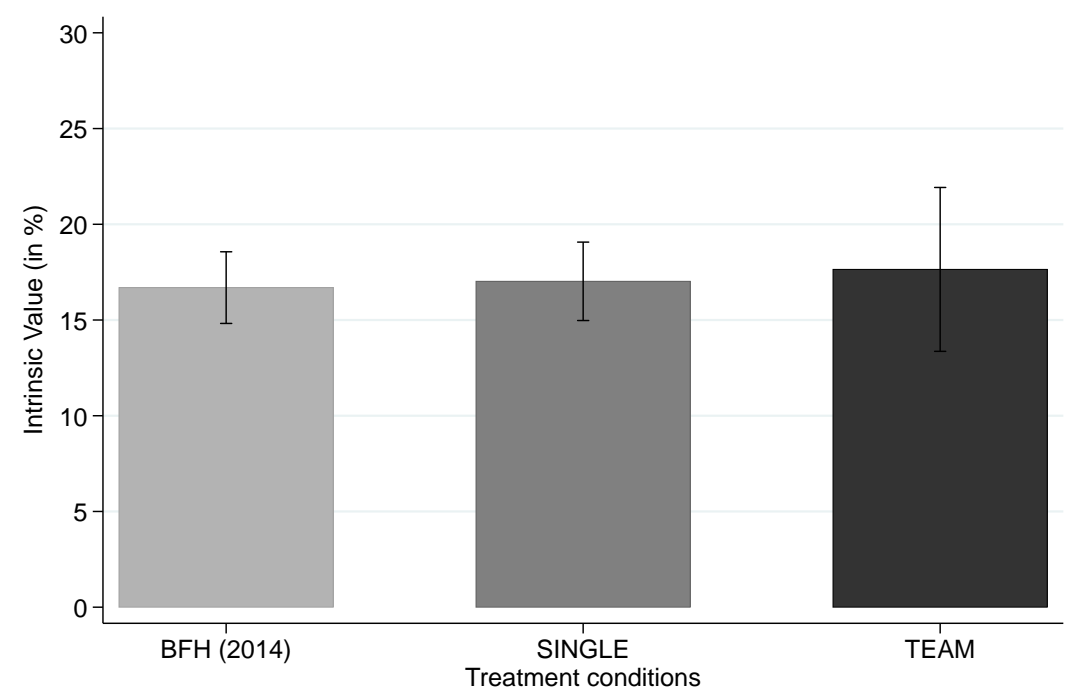

Figure 1: Percentage $I V$ difference for BFH's original data and treatments SINGLE and TEAM. Error bars represent the standard errors at means (average \pm SEM).

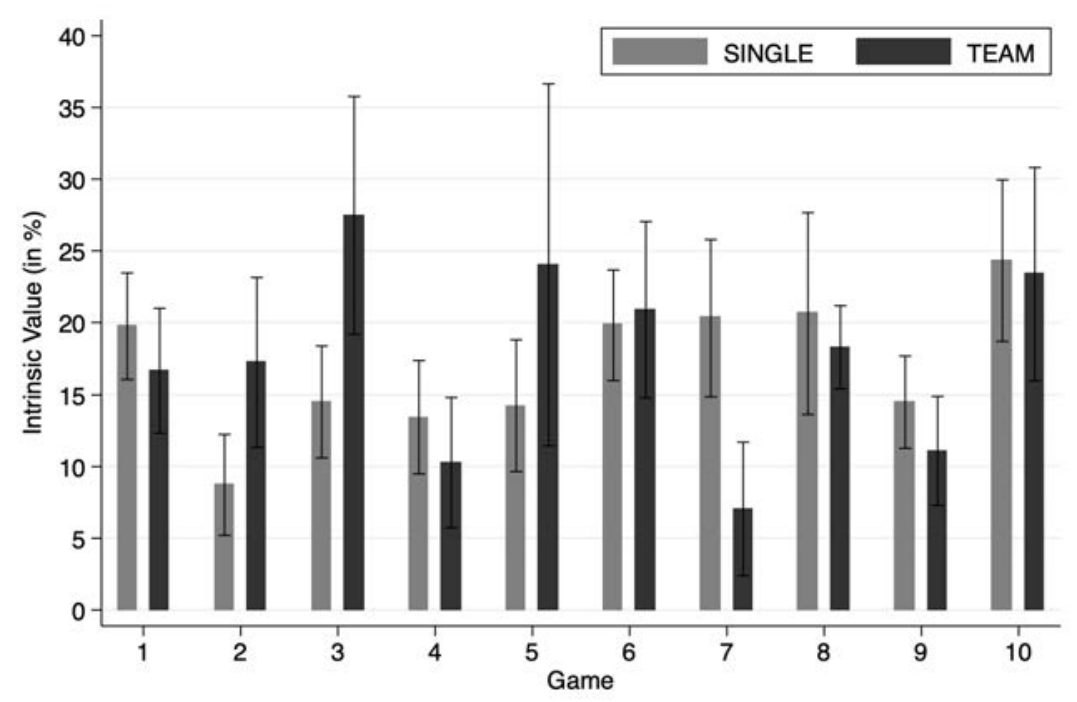

Figure 2: Percentage $I V$ difference for treatments SINGLE and TEAM at the game level. Error bars represent the standard errors at means (average $\pm \mathrm{SEM}$ ). 


\subsection{A deeper analysis of team decision-making: distinguishing between smooth and conflict teams}

Recall that team decisions had to be made unanimously, since both team members had to agree on the same choice. The requirement of unanimity may have created conflict, though, between team members. In fact, in the post-experimental questionnaire we see that 10 out of 60 subjects in the role of a principal (role A) were dissatisfied with the team decision making procedure by either indicating that they felt excluded from the process or that they gave up in the process. 13 The 10 subjects came from 9 different teams. We are going to refer to these nine teams as the "conflict teams" henceforth, because at least one team member was dissatisfied with the decision making process. In the remaining 21 teams ${ }^{14}$ both team members did not indicate any problems in the process, for which reason we call them the "smooth teams".

Before we investigate the impact of conflict in teams on the intrinsic value of decision rights, we want to back up our questionnaire-based distinction between smooth and conflict teams by looking also at quantitative features of the decision making process, i.e., the ease with which team members could agree on a decision and the concomitant extent of communication.

First, we focus on the agreement rate between team members on the very first proposal they individually make before they confirm the team decision. Figure 3 shows the fraction of initial agreement between team members regarding (a) the minimum effort required from the agent and (b) the own effort if the decision is not delegated. Both graphs suggest that smooth teams agreed more often on their first proposal than conflict teams. The rate over all 10 delegation games is $89 \%$ for smooth teams, and $72 \%$ for conflict teams ( $p=0.029$, one-tailed Mann-Whitney U-test). The same pattern emerges for the rate of agreement on the own effort proposal. The overall rate is $87 \%$ for smooth teams, and $68 \%$ for conflict teams ( $p=0.042$, onetailed Mann-Whitney U-test). Please recall that team members could use the chat function to discuss proposals even before any team member entered a proposal. This feature was used by many teams and explains the generally high agreement rates.

\footnotetext{
${ }^{13}$ Out of these 10 subjects, 3 felt excluded, 3 gave up, and 4 answered positively to both questions.

${ }^{14}$ Recall that we had 60 participants in role $\mathrm{A}$ in treatment TEAM, which means that we had 30 independent teams in total, nine of which had conflicts.
} 


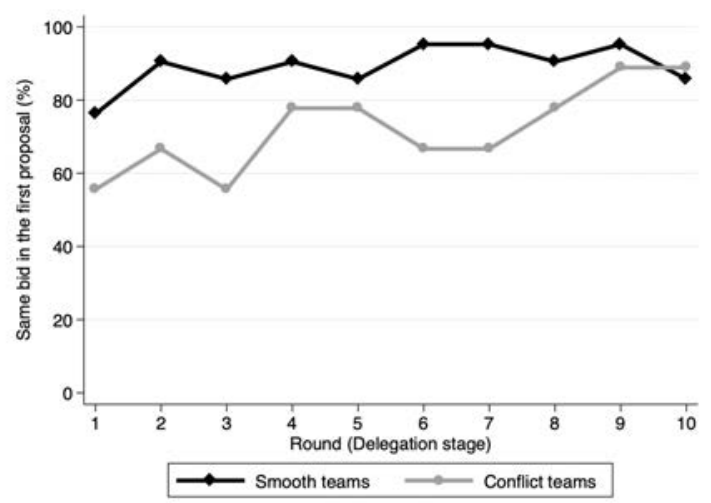

(a) Minimum effort requirement

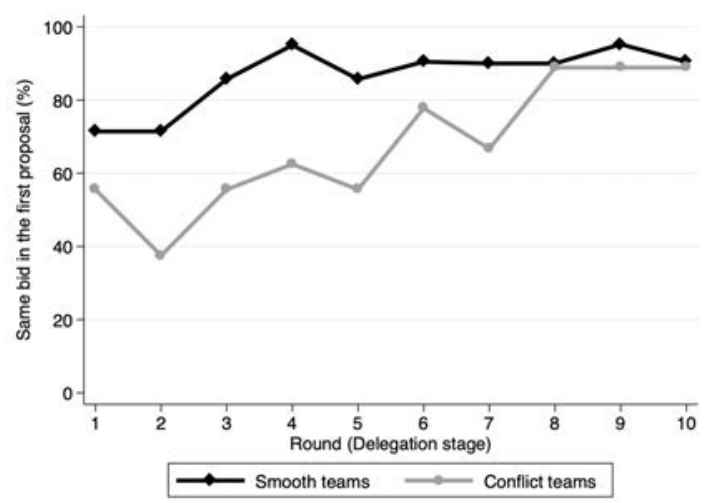

(b) Effort

Figure 3: Agreement rates between team members for the first proposal regarding (a) the minimum effort required from the agent and (b) the chosen effort in case of no delegation, separately for both types of teams and for the 10 rounds in the principal-agent part.

To better understand why the agreement rate is lower for conflict teams, we take a closer look at the sequence of events in the principal-agent part. In particular, we investigate to what extent team members use the free-text chat tool to agree on a joint decision before confirming it. Recall that in the principal-agent part, team members make three sequential decisions: the minimum effort required from the agent, the project alternatives and the effort level in case they retain the decision right. At any time in a given round, team members can freely exchange chat messages. Once each member has individually selected her choices, a summary displays the decisions of both members with the possibility to revise their decisions and to agree on joint decisions.

Figure 4 displays the fraction of team members confirming their suggested proposal on the minimum effort requirement before chatting with the other team member. It seems straightforward that confirming one's proposal without discussing the issue with the other team member indicates poor communication within a team and may be the reason for indicating a conflict in the team decision making process in the post-experimental questionnaire. Here we use the data for the minimum effort requirement as the first event within each round, because it happens that the decisions about the own project alternative and the own effort are often already discussed when still making a decision about the minimum effort requirement for the agent. This means that for the second and third decision (own project and own effort) it is much more difficult to cleanly separate the order of events (communication and decision) and only the first decision in a round (about the minimum effort requirement for agents) is not confounded.

We see from Figure 4 that members of conflict teams are much more likely to confirm a proposal individually before chatting with the other team member than members of smooth teams do (33.3\% vs. 9.52\%, $p=0.013$, one-tailed Mann-Whitney U-test). We interpret this result as evidence that members of conflict teams are less communicative than members of smooth teams in finding an agreement. 


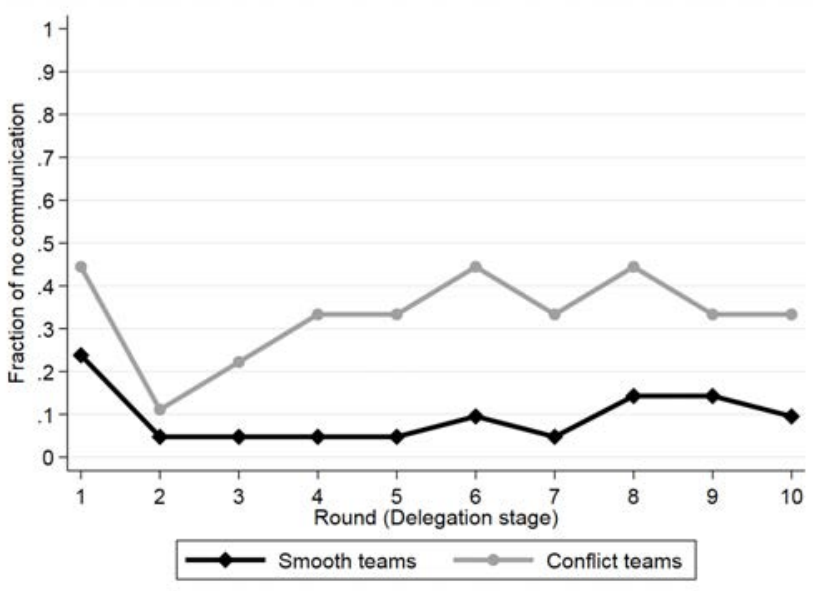

Figure 4: Fraction of team members not chatting with the other member before confirming their proposal on the minimum effort requirement in the principal-agent part.

Result 2. Both the post-experimental questionnaire and an analysis of the decision making process with respect to the ease of agreement and extent of communication suggest that there are two types of teams, one with conflicts in decision making ("conflict teams") and one without ("smooth teams").

\subsection{Smooth vs. conflict teams and the intrinsic value of decision rights}

Figure 5 shows the intrinsic value of decision rights (in \%) for the two types of teams identified in the previous subsection, and for comparison reasons also for SINGLE. We see that smooth teams value decision rights much less than individuals ( $8.6 \%$ vs. $17.0 \%)$, and this difference is highly significant (t-test, $p<0.01$, and two-tailed Mann-Whitney U-test, $p=0.03$ ). This finding suggests that teams who experience no conflict in the decision making process are less attached to decision rights per se, but rather care for the instrumental value. Much to the contrary, Figure 5 shows that the intrinsic value for conflict teams is very high with $38.7 \%$ and significantly larger than in SINGLE and in smooth teams ( $p<0.05$ in any comparison, both with t-tests and two-tailed Mann-Whitney U-tests) 15

${ }^{15}$ In Appendix A.3. Figure S2 shows that our results are independent of the stake sizes. 


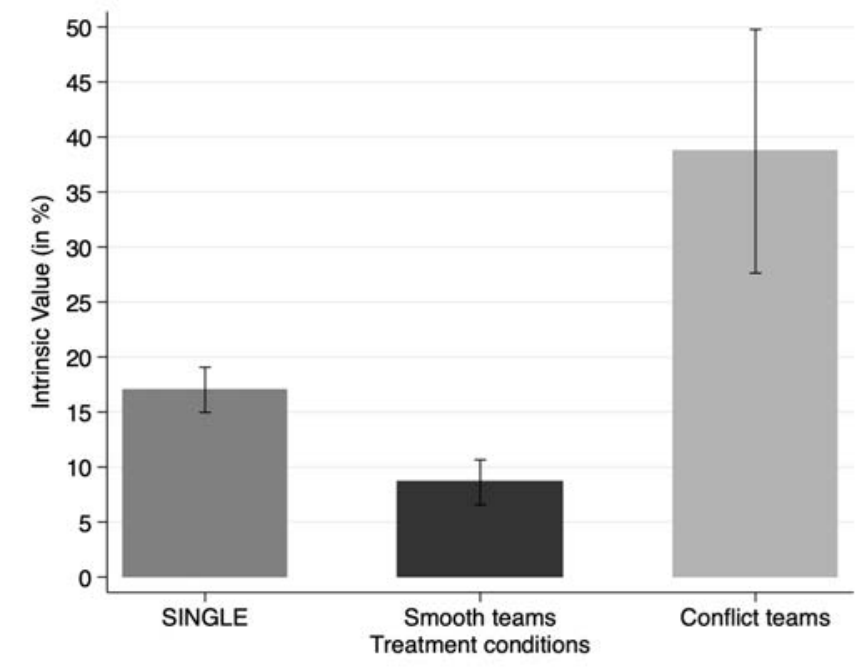

Figure 5: Percentage IV difference for treatment SINGLE, smooth teams and conflict teams at the aggregated level. Error bars represent the standard errors at means (average \pm SEM).

Figure 6 shows the intrinsic value for the 10 different delegation games separately. In all cases, the intrinsic value is smaller for smooth teams than for conflict teams, ${ }^{16}$ A remarkable insight when looking at the intrinsic value for smooth teams is the fact that it is not significantly different from zero for four out of ten games (for games 2, 4, 5, 7, t-tests, $p>0.1$ ). Recall that this is never the case for individual decision makers (see Figure 2 above). Obviously, teams without conflicts in the decision making process care much more about the instrumental value of decision rights, and only in slightly more than half of the cases they attach in addition an intrinsic, albeit small, value to decision rights 17

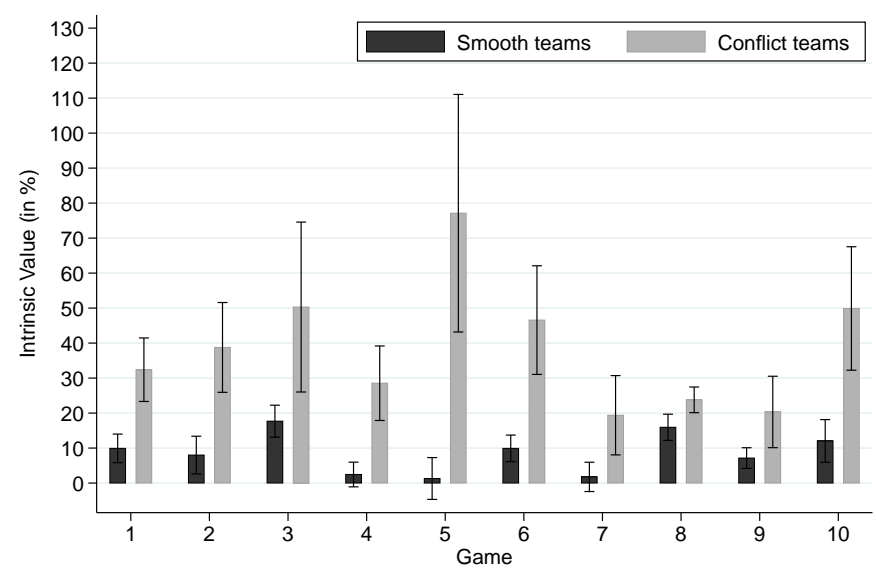

Figure 6: Percentage IV difference for smooth teams and conflict teams at the game level. Error bars represent the standard errors at means (average \pm SEM).

${ }^{16}$ We have $p<0.05$ according to two-sided t-tests for each game, except for game 3 ( $\left.p=0.07\right)$, game $7(p=0.08)$, game $8(p=0.21)$, and game $9(p=0.11)$. OLS regressions in Table S4 show statistical significance for 5 games with $p<0.05$ (games 1, 2, 4, 5 and 6) and one game with $p=0.052$ (game 10).

${ }^{17}$ When comparing data in SINGLE with smooth teams, we see statistical differences in $I V \%$ for six out of ten delegation games (\# 1, 4, 5, 6, 7, and 9; see Table S2 in Appendix A.2 and Figure S3. 
Result 3. Smooth teams have a significantly lower intrinsic value (8.6\%) than individuals (17\%), while conflict teams have a very high intrinsic value for decision rights (38.7\%). For smooth teams, the intrinsic value for 4 out of 10 delegation games is actually not significantly different from zero.

\section{Conclusion}

Organizations, and in particular its shareholders, care primarily about the outcome of decisions, and not about whether or not decision makers have a positive valuation of decision rights. Positive intrinsic values of decision rights may confound a principal's choice of whether or not to delegate a particular decision to an agent. This may then diminish the weight put on the instrumental value of decision rights and may thus lead to suboptimal choices. In fact, recent work has shown that many individuals have positive intrinsic values of decision rights (see e.g. Bartling et al. 2014; Ferreira et al. 2020). It has not been addressed, however, whether teams also have such positive intrinsic values. Given the ever increasing importance of team decision making in organizations it is important to study the valuation of decision rights for teams as well. This has been the main purpose of our paper.

Based on the stylized findings of the previous literature that teams are more rational decision makers that care more about payoff-maximization and are less behavioral (see e.g. Feri et al., 2010: Charness and Sutter, 2012, Kugler et al., 2012, Kocher et al., 2020), we have expected lower intrinsic values of decision rights in teams than in individuals. Using the seminal design of Bartling et al. (2014) to measure the valuation of decision rights, we have not found any differences in the aggregate behavior of individuals and teams, however. For individuals, our data provide a remarkably accurate replication of the findings in Bartling et al. (2014), and for teams (of two subjects each) it looks similar at first sight.

A closer inspection of team decision reveals an important distinction between two types of teams, though. Since the two team members had to agree unanimously on the team's decision, this generated conflicts in some teams, and team members then expressed dissatisfaction with the decision making procedure and the communication within teams. From this observation we have been able to distinguish between teams with and those without conflicts, backing up our classification with quantitative evidence about the ease of agreement and the extent of communication. The smoothly functioning teams show a very different behavior from teams with conflicts, and we consider this an important insights for the management of organizations.

Teams without frictions in the decision making process have much lower intrinsic values of decision rights - lower than for individuals and lower than for teams with conflicts. In almost half of the choices, the intrinsic value is not even different from zero for smooth teams. This means that the instrumental value of decision rights is the major driver of behavior of such teams. So, from an organizational point of view, team decision making may be good for making optimal, or at the least better, decisions, but our results stress the fact that this may only work when the decision making process within teams works smoothly and is frictionless. 
Not surprisingly, in case of conflict within teams the quality of decision making deteriorates. The novel contribution of our paper has been to identify the problems arising from conflict within teams for the intrinsic or instrumental valuation of decision rights. According to our results, organizations could benefit from screening the decision making process within teams, because it is well reflected in the (potentially suboptimal) decisions of teams.

Future research may also provide additional insights for organizations when it studies how hierarchy within teams affects the intrinsic value of decision rights. If one team leader, for example, has the right of ultimately deciding on behalf of a whole work-team, such a situation is very similar to individual decision making, with the big difference that such an individual decision has an externality on the other team members. It is an open question whether this would affect how teams, respectively team leaders, assess the instrumental or intrinsic value of decision rights, and whether this is more or less beneficial for organizations. From a theoretical perspective, our results provide compelling evidence for the elaboration of a theory that accounts for conflicts within teams and takes the potential consequences of conflict into account when modeling team decisions (Sobel, 2006). We consider such questions as promising avenues for future research. 


\section{References}

Bandiera, O., Barankay, I., and Rasul, I. (2013). Team incentives: Evidence from a firm level experiment. Journal of the European Economic Association, 11(5), 1079-1114.

Bartling, B., Fehr, E., and Herz, H. (2014). The intrinsic value of decision rights. Econometrica, 82(6), 2005-2039.

Becker, G. M., DeGroot, M. H., and Marschak, J. (1964). Measuring utility by a single-response sequential method. Behavioral Science, 9(3), 226-232.

Bohnet, I. and Zeckhauser, R. (2004). Trust, risk and betrayal. Journal of Economic Behavior E Organization, 55(4), $467-484$.

Bohnet, I., Greig, F., Herrmann, B., and Zeckhauser, R. (2008). Betrayal aversion: Evidence from Brazil, China, Oman, Switzerland, Turkey, and the United States. American Economic Review, 98(1), pp. 294-310.

Bolton, G. E., Brandts, J., and Ockenfels, A. (2005). Fair procedures: Evidence from games involving lotteries. The Economic Journal, 115(506), 1054-1076.

Carnevale, P. J. and Lawler, E. J. (1986). Time pressure and the development of integrative agreements in bilateral negotiations. Journal of Conflict Resolution, 30(4), 636-659.

Charness, G. and Sutter, M. (2012). Groups make better self-interested decisions. Journal of Economic Perspectives, 26(3), 157-176.

Chlaß, N., Güth, W., and Miettinen, T. (2019). Purely procedural preferences-beyond procedural equity and reciprocity. European Journal of Political Economy, 59, 108-128.

Cooper, D. J. and Kagel, J. H. (2005). Are two heads better than one? team versus individual play in signaling games. American Economic Review, 95(3), 477-509.

Dold, M. and Khadjavi, M. (2017). Jumping the queue: An experiment on procedural preferences. Games and Economic Behavior, 102, 127-137.

Fehr, E., Herz, H., and Wilkening, T. (2013). The lure of authority: Motivation and incentive effects of power. American Economic Review, 103(4), 1325-1359.

Feri, F., Irlenbusch, B., and Sutter, M. (2010). Efficiency gains from team-based coordinationlarge-scale experimental evidence. American Economic Review, 100(4), 1892.

Ferreira, J. V., Hanaki, N., and Tarroux, B. (2020). On the roots of the intrinsic value of decision rights: Evidence from france and japan. Games and Economic Behavior, 119, 110-122.

Fischbacher, U. (2007). z-tree: Zurich toolbox for ready-made economic experiments. Experimental Economics, 10(2), 171-178. 
Graham, J. R., Harvey, C. R., and Puri, M. (2015). Capital allocation and delegation of decisionmaking authority within firms. Journal of Financial Economics, 115(3), 449-470.

Greiner, B. (2015). Subject pool recruitment procedures: organizing experiments with ORSEE. Journal of the Economic Science Association, 1(1), 114-125.

Grossman, S. J. and Hart, O. D. (1986). The costs and benefits of ownership: A theory of vertical and lateral integration. Journal of Political Economy, 94(4), 691-719.

Hart, O. and Moore, J. (1990). Property rights and the nature of the firm. Journal of Political Economy, 98(6), 1119-1158.

Keck, S., Diecidue, E., and Budescu, D. (2014). Group decisions under ambiguity: Convergence to neutrality. Journal of Economic Behavior and Organization, 103, 60-71.

Kocher, M. G., Schindler, D., Trautmann, S. T., and Xu, Y. (2019). Risk, time pressure, and selection effects. Experimental Economics, 22(1), 216-246.

Kocher, M. G., Praxmarer, M., and Sutter, M. (2020). Team decision-making. In K. F. Zimmermann, editor, Handbook of Labor, Human Resources and Population Economics. Springer International Publishing, 1-25.

Kugler, T., Kausel, E. E., and Kocher, M. G. (2012). Are groups more rational than individuals? a review of interactive decision making in groups. Wiley Interdisciplinary Reviews: Cognitive Science, 3(4), 471-482.

Lazear, E. P. and Shaw, K. L. (2007). Personnel economics: The economist's view of human resources. Journal of Economic Perspectives, 21(4), 91-114.

Maciejovsky, B., Sutter, M., Budescu, D. V., and Bernau, P. (2013). Teams make you smarter: How exposure to teams improves individual decisions in probability and reasoning tasks. Management Science, 59(6), 1255-1270.

Neri, C. and Rommeswinkel, H. (2017). Decision rights: freedom, power, and interference. Technical report, Working Paper, Available at SSRN: https:/ /ssrn.com/abstract=2485107, .

Owens, D., Grossman, Z., and Fackler, R. (2014). The control premium: A preference for payoff autonomy. American Economic Journal: Microeconomics, 6(4), 138-161.

Priem, R. L., Harrison, D. A., and Muir, N. K. (1995). Structured conflict and consensus outcomes in group decision making. Journal of Management, 21(4), 691-710.

Sobel, J. (2006). Information aggregation and group decisions. University of California, San Diego - Working Paper.

Spiliopoulos, L. and Ortmann, A. (2018). The bcd of response time analysis in experimental economics. Experimental Economics, 21(2), 383-433. 


\section{A Online Appendix}

\section{A.1 Comparison of treatment SINGLE with BFH (2014)}

Figure $\mathrm{S1}$ provides the average value of $I V \%$ at the game level and for both treatments. In every delegation game each measured $I V$ in our data for individual decision makers is strictly positive, and is significantly different from zero for each of the ten delegation games (Wilcoxonsigned-rank tests, all $p<0.01$, except for game 2, $p<0.03$ ). 18 Except for game 9, there is no significant difference between the IV\% in BFH and our data in SINGLE 19

Overall, the data show that our treatment SINGLE is a strong replication of BFH (2014) and the slightly different wording and different subject pool that we used had no effect on decision-making.

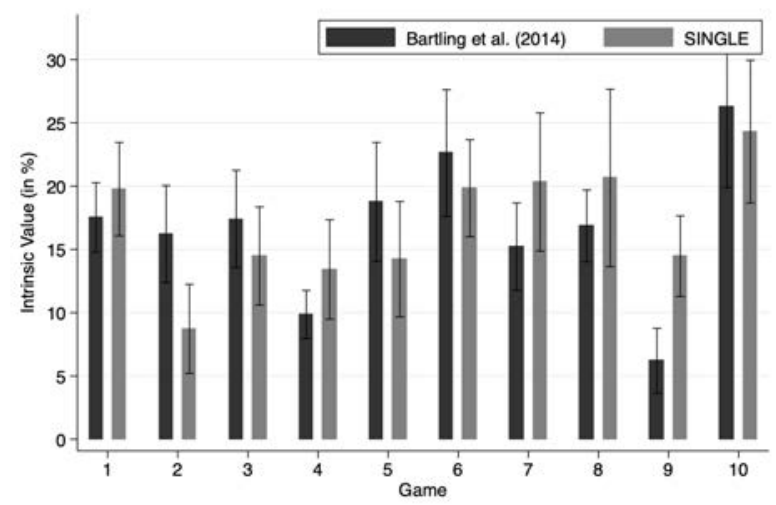

Figure S1: Percentage IV difference for the individual condition in BFH (2014) and treatment SINGLE at the game level (panel b). Error bars represent standard errors at means (average \pm $S E M)$ clustered at the decision maker-level.

\section{A.2 Additional Tables}

Table S1: IV\%: TEAM vs SINGLE for each of the 10 games.

\begin{tabular}{lcccccccccc}
\hline & \multicolumn{1}{c}{$(1)$} & $(2)$ & $(3)$ & $(4)$ & $(5)$ & $(6)$ & $(7)$ & \multicolumn{1}{c}{$(8)$} & \multicolumn{1}{c}{$(9)$} & $(10)$ \\
\hline TEAM & -0.031 & 0.085 & 0.130 & -0.031 & 0.098 & 0.011 & $-0.133^{*}$ & -0.024 & -0.034 & -0.009 \\
& $(0.057)$ & $(0.069)$ & $(0.091)$ & $(0.060)$ & $(0.133)$ & $(0.072)$ & $(0.072)$ & $(0.076)$ & $(0.049)$ & $(0.093)$ \\
Constant & $0.198^{* * *}$ & $0.087^{* *}$ & $0.145^{* * *}$ & $0.134^{* * *}$ & $0.142^{* * *}$ & $0.198^{* * *}$ & $0.203^{* * *}$ & $0.206^{* * *}$ & $0.145^{* * *}$ & $0.243^{* * *}$ \\
& $(0.037)$ & $(0.035)$ & $(0.039)$ & $(0.039)$ & $(0.046)$ & $(0.038)$ & $(0.055)$ & $(0.070)$ & $(0.032)$ & $(0.057)$ \\
\hline$R^{2}$ & 0.003 & 0.019 & 0.029 & 0.003 & 0.009 & 0.000 & 0.028 & 0.001 & 0.005 & 0.000 \\
Observations & 90 & 90 & 90 & 90 & 90 & 90 & 90 & 90 & 90 & 90
\end{tabular}

Notes: OLS regressions. Each column represents one of the 10 games. The dependent variable is IV\%. TEAM (NoIssues) is a dummy for teams without issues. The reference group is SINGLE. Levels of significance: ${ }^{*} p<0.1,{ }^{* *} p<0.05,{ }^{* * *} p<0.01$.

\footnotetext{
${ }^{18} \mathrm{~A}$ t-test supports the results: all $p<0.01$, except for game $2, p<0.02$

${ }^{19} \mathrm{The} I V \%$ in game 9 is $6.2 \%$ in $\mathrm{BFH}$ and $14.5 \%$ in our data, and this difference is statistically significant (t-test, $p=0.05$ and Mann-Whitney U-test, $p=0.03$ ).
} 
Table S2: IV\%: Smooth teams vs SINGLE for each of the 10 games.

\begin{tabular}{lccccccrrrrr}
\hline & $(1)$ & $(2)$ & $(3)$ & $(4)$ & $(5)$ & $(6)$ & $(7)$ & $(8)$ & $(9)$ & $(10)$ \\
\hline Smooth teams & $-0.099^{*}$ & -0.007 & 0.032 & $-0.110^{* *}$ & $-0.129^{*}$ & $-0.099^{*}$ & $-0.186^{* * *}$ & -0.047 & $-0.073^{*}$ & -0.123 \\
& $(0.054)$ & $(0.063)$ & $(0.059)$ & $(0.052)$ & $(0.074)$ & $(0.054)$ & \multicolumn{1}{c}{$(0.068)$} & $(0.079)$ & $(0.043)$ & $(0.082)$ \\
Constant & $0.198^{* * *}$ & $0.087^{* *}$ & $0.145^{* * *}$ & $0.134^{* * *}$ & $0.142^{* * *}$ & $0.198^{* * *}$ & $0.203^{* * *}$ & $0.206^{* * *}$ & $0.145^{* * *}$ & $0.243^{* * *}$ \\
& $(0.037)$ & $(0.035)$ & $(0.039)$ & $(0.039)$ & $(0.046)$ & $(0.038)$ & $(0.055)$ & $(0.070)$ & $(0.032)$ & $(0.057)$ \\
\hline$R^{2}$ & 0.027 & 0.000 & 0.003 & 0.030 & 0.028 & 0.026 & 0.045 & 0.002 & 0.021 & 0.018 \\
Observations & 81 & 81 & 81 & 81 & 81 & 81 & 81 & 81 & 81 \\
\hline
\end{tabular}

Notes: OLS regressions. Each column represents one of the 10 games. The dependent variable is IV\%. Smooth team is a dummy for teams without issues. The reference group is SINGLE. Levels of significance: ${ }^{*} p<0.1,{ }^{* *} p<0.05,{ }^{* * *} p<0.01$.

Table S3: IV\%: Conflict teams vs SINGLE for each of the 10 games.

\begin{tabular}{lcccccccccc}
\hline & $(1)$ & $(2)$ & \multicolumn{1}{c}{$(3)$} & \multicolumn{1}{c}{$(4)$} & \multicolumn{1}{c}{$(5)$} & \multicolumn{1}{c}{$(6)$} & \multicolumn{1}{c}{$(7)$} & \multicolumn{1}{c}{$(8)$} & \multicolumn{1}{l}{$(9)$} & $(10)$ \\
\hline Conflict teams & 0.126 & $0.300^{* *}$ & 0.358 & 0.151 & $0.629^{*}$ & $0.267^{*}$ & -0.009 & 0.031 & 0.059 & 0.256 \\
& $(0.096)$ & $(0.131)$ & $(0.241)$ & $(0.112)$ & $(0.336)$ & $(0.157)$ & $(0.124)$ & $(0.079)$ & $(0.105)$ & $(0.182)$ \\
Constant & $0.198^{* * *}$ & $0.087^{* *}$ & $0.145^{* * *}$ & $0.134^{* * *}$ & $0.142^{* * *}$ & $0.198^{* * *}$ & $0.203^{* * *}$ & $0.206^{* * *}$ & $0.145^{* * *}$ & $0.243^{* * *}$ \\
& $(0.037)$ & $(0.035)$ & $(0.039)$ & $(0.040)$ & $(0.046)$ & $(0.039)$ & $(0.055)$ & $(0.071)$ & $(0.032)$ & $(0.057)$ \\
\hline$R^{2}$ & 0.022 & 0.111 & 0.093 & 0.028 & 0.161 & 0.074 & 0.000 & 0.000 & 0.006 & 0.036 \\
Observations & 69 & 69 & 69 & 69 & 69 & 69 & 69 & 69 & 69 & 69 \\
\hline
\end{tabular}

Notes: OLS regressions. Each column represents one of the 10 games. The dependent variable is IV\%. Conflict team is a dummy for teams with issues. The reference group is SINGLE. Levels of significance: ${ }^{*} p<0.1,{ }^{* *} p<0.05,{ }^{* * *} p<0.01$.

Table S4: IV\%: Smooth teams vs conflict teams for each of the 10 games.

\begin{tabular}{lcccccccccc}
\hline & $(1)$ & $(2)$ & $(3)$ & $(4)$ & \multicolumn{1}{c}{$(5)$} & \multicolumn{1}{c}{$(6)$} & \multicolumn{1}{c}{$(7)$} & \multicolumn{1}{c}{$(8)$} & \multicolumn{1}{c}{$(9)$} & $(10)$ \\
\hline Smooth teams & $-0.225^{* *}$ & $-0.308^{* *}$ & -0.326 & $-0.261^{* *}$ & $-0.758^{* *}$ & $-0.367^{* *}$ & -0.176 & -0.078 & -0.132 & $-0.379^{*}$ \\
& $(0.099)$ & $(0.139)$ & $(0.247)$ & $(0.112)$ & $(0.345)$ & $(0.160)$ & $(0.121)$ & $(0.052)$ & $(0.106)$ & $(0.187)$ \\
Constant & $0.324^{* * *}$ & $0.388^{* * *}$ & $0.503^{* *}$ & $0.285^{* *}$ & $0.771^{* *}$ & $0.466^{* * *}$ & $0.194^{*}$ & $0.238^{* * *}$ & $0.203^{*}$ & $0.499^{* * *}$ \\
& $(0.091)$ & $(0.128)$ & $(0.243)$ & $(0.106)$ & $(0.339)$ & $(0.155)$ & $(0.113)$ & $(0.037)$ & $(0.102)$ & $(0.176)$ \\
\hline$R^{2}$ & 0.196 & 0.197 & 0.112 & 0.239 & 0.262 & 0.259 & 0.104 & 0.054 & 0.087 & 0.189 \\
Observations & 30 & 30 & 30 & 30 & 30 & 30 & 30 & 30 & 30 & 30 \\
\hline
\end{tabular}

Notes: OLS regressions. Each column represents one of the 10 games. The dependent variable is IV\%. Smooth team is a dummy for teams without issues. The reference group is conflict teams, i.e., teams with issues. Levels of significance: ${ }^{*} p<0.1,{ }^{* *} p<0.05,{ }^{* * *} p<0.01$.

\section{A.3 The influence of stakes}

The experimental design allows us to control for the effect of the size of stakes because the stakes in games 6 to 10 are twofold the stakes in games 1 to 5 (see Table 1). Figure S2 displays the intrinsic value for SINGLE, smooth teams, and conflict teams over low and high stakes. As in BFH (2014), the larger the stakes the higher the intrinsic value of individual decision makers (from $14.1 \%$ to $19.9 \%$, paired t-test, $p=0.07$ ). For smooth teams, however, stakes do not significantly affect their intrinsic value (7.9\% for low stakes, $9.4 \%$ for high stakes, paired t-test, $p=0.64)$. The difference in the intrinsic value between treatment SINGLE and smooth teams is marginally significant for low stakes (t-test, $p<0.1$ and Mann-Whitney U-test, $p=0.11$ ) and significant 
for high stakes (t-test, $p<0.01$ and Mann-Whitney U-test, $p<0.05$ ). Further, we can observe that conflict teams report a higher intrinsic value than individuals. This difference is significant for low stakes situations (t-test, $p<0.05$ and Mann-Whitney U-test, $p<0.01$ ), but fails to be significant for high stakes situations ( $p>0.1$, for t-test and Mann-Whitney U-test).

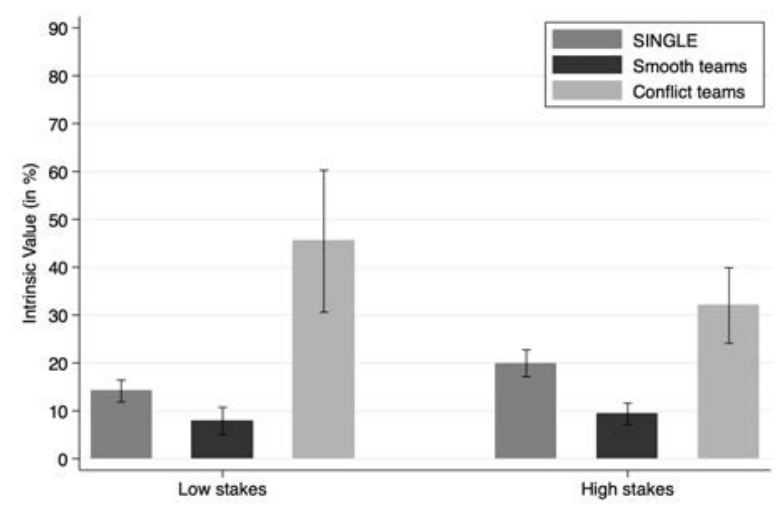

Figure S2: Percentage IV difference for treatment SINGLE, smooth teams, and conflict teams for different stake sizes.

\section{A.4 Smooth and conflict teams at the game level}

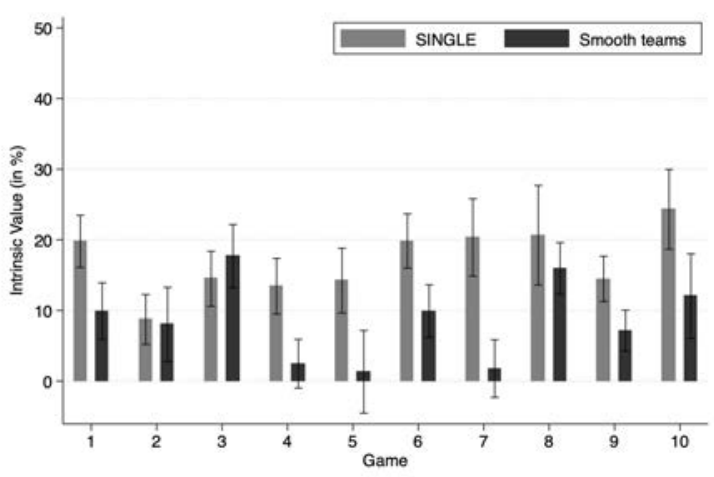

(a) Delegation games smooth teams

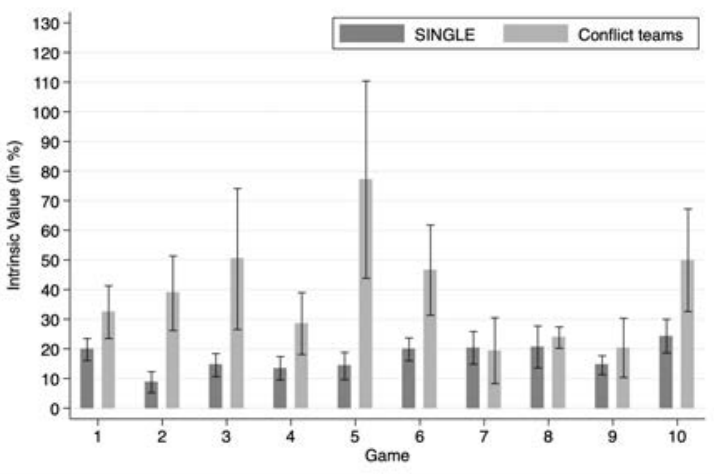

(b) Delegation games conflict teams

Figure S3: Comparison of SINGLE with smooth teams and conflict teams for single games. Error bars represent standard errors at means (average $\pm S E M$ ) clustered at the decision maker-level. 


\section{A.5 Experimental Instructions}

\section{A.5.1 Instructions - Part 1}

\section{Instructions for role A 20}

Welcome to today's experiment. You receive 4 Euros as a show-up fee. During the experiment you will be asked to make decisions and so will the other participants. Your decisions, as well as the decisions of the other participants, will determine your monetary payoff. Therefore, it is important that you carefully read the instructions. If you have any questions during the experiment, please raise your hand and one of the experimenters will come to assist you.

Please do not communicate with other participants before the end of the experiment. Please switch off your mobile phone. In addition, we want to point out that you are only allowed to use the computer functions that are intended for the course of the study. If you violate these rules, you will be immediately excluded from the experiment and all payments. At the end of the experiment we will pay you in cash $€ 4$ as a show-up fee and the money you've earned during the experiment. Your income in the experiment will be in "points". At the end of the experiment, points will be converted into euro at an exchange rate of

\section{Points $=2$ Euros}

This study consists of three parts:

1. The first part of the study lasts 10 rounds. (In each of the 10 rounds you are paired with another participant (always the same person). Together you represent role A. You will be called team members A1 and A2. You learn at the beginning of the experiment if you are A1 or A2.) You will be paired with a different role B in each of the 10 rounds of the study. You can complete a project with the role B who is paired with you in each round. You will find detailed explanations about this first part of the study on the following pages.

2. You will receive exact instructions about the second part as soon as the first part is completed.

3. The third part of the study is very short, and you will receive instructions on screen as soon as the second part is completed.

\footnotetext{
${ }^{20}$ Modification for treatment TEAM in red and in parenthesis.
} 


\section{General information about the first part of the study}

There are two types of roles in the first part of the study: role A and role B. You are (part of) role A. (Role A consists of two fixed matched participants. Role B consists of a single person. Role B knows that your role consists of two team members.)

There are ten rounds. You (Role A (you and your team partner)) will be paired with a different role B in each round. A project can be completed in each round. A successful completion of the project will lead to a positive payment for roles A and B.

\section{The decision right}

In each period, either you (and your team partner) (role A) or role B has the decision right. The role with the decision right can make two decisions:

\section{Which alternative of the project - A or B - will be completed?}

Role A receives the larger share of the project income in alternative $\mathrm{A}$, and role $\mathrm{B}$ receives the larger share of the project income in alternative B. (It is possible that roles A and B will receive the same amounts in some rounds.)

\section{What is the probability that the project will be successful?}

The determination of the probability of success is associated with costs for the role with the decision right. The higher the probability of success, the higher the costs.

\section{Payment of the project}

The payments that result from completion of the project vary from round to round. You will be informed of the payments at the beginning of each round.

Example: The payments from the project in a round: In case of success, you (role A (your team)) will receive 200 points (per person) in alternative A and role B will receive 150 points. Role B will reiceve 200 points in case of success in alternative B and you (role A (your team)) will recieve 150 points (per person). If the project is unsuccessful, role A (your team) receives 100 points (per person) and role $B$ receives 100 points.

\begin{tabular}{|c|c|c|c|}
\hline & & $\begin{array}{c}\text { Payment to } \\
\text { role A (per person) }\end{array}$ & Payment to role B \\
\hline \multirow{2}{*}{ Successful completion } & Alternative A & 200 & 150 \\
\cline { 2 - 4 } & Alternative B & 150 & 200 \\
\hline \multicolumn{2}{|r|}{ If unsuccessful } & 100 & 100 \\
\hline
\end{tabular}




\section{The probability of success}

If you, role $\mathrm{A}$, have the decision right, then you can determine the probability with which the chosen project alternative - A or B - will be successful.

\section{How is the probability of success determined?}

The prbability of success is a number between 0 and 100 that can be chosen freely.

$$
\mathbf{0} \leq \text { probability of success } \leq \mathbf{1 0 0}
$$

A probability of success of 0 means that the project will never be successful. A probability of success of 100 means that the project will always be successful. For all values in between, a project might be successful or it might not be so. A value of 50 means that a project has a $50 \%$ chance of being successful.

If the project is successful, roles $A$ and $B$ will be paid out in accordance to the chosen alternative (in the example above, 150 or 200 points). If the project is not successful, both participants will receive a lower payment independent of the chosen alternative (in the example above, 100 points each).

\section{The costs of the choice of the probability of success}

The higher the probability of success you choose, the higher are your costs. Two information sheets (yellow and pink) are at your desk; they show you both in a table and in a graph how high the costs are for the various possible probabilities of success. You will be informed in each round whether the costs on the yellow or on the pink sheet apply. You can also always have the computer show you the costs on the monitor while choosing the probability of success.

\section{A roll of the dice determines whether the project is successful}

The role with the decision right can roll two dice at his or her desk - they are red and white (and show the numbers from 0 to 9). The red die determines the first digit and the white the second digit. This results in a number between 1 and 100 (two zeros are valued as 100). If the number rolled is smaller than or equal to the chosen probability of success, the project is successful. If the number rolled is larger, the project is not successful. The greater the probability of success that you choose, the greater the possibility that the number rolled is smaller than the chosen number, i.e., that the project is successful. 
Examples:

1. Example: You choose a probability of success of 15, i.e., $15 \%$

This means the following:

- If - through rolling the red and the white dice - a smaller or equal number results, i.e. a number between 1 and 15 (= 15 of 100 possibilities), the project is successful.

- If the number is greater than 15 (= 16 to 100 , or 85 possibilities) results, then the project is not successful.

2. Example: You choose $\mathbf{8 0}$ as the probability of success, i.e., a probability of success of $80 \%$.

This means the following:

- If - through rolling the red and the white dice - a number between 1 and 80 (= 80 of 100 possibilities), the project is successful.

- If the number is greater than 80 (= 81 to 100 , or 20 possibilities) results, then the project is not successful.

- Assume that you roll the number 9 with the red die and a 3 with the white one. This results in the number 93.

In this case, neither example would have been successful (the number rolled is, in both cases, larger than the chosen probability of success).

- Assume that you roll the number 5 with the red die and a 4 with the white one. This results in the number 54 .

In this case, the project in the first example would not have been successful (the number rolled is larger than 15), but the project in the second example would have been successful (the number rolled is less than 80).

- Assume that you roll the number 0 with the red die and a 3 with the white one. This results in the number 03.

In this case, the project would have been successful in both examples (the number rolled is less than the probability of success chosen in each example). 


\section{The income}

The incomes of roles A and B consist of the following two parts:

- Payment from the chosen project alternative if the project is successful. If the project is not successful, both roles receive a lower payment that is independent of the project alternative.

- The costs for the probability of success will be deducted from the corresponding payment for the role with the decision right.

The following four possibilites thus result for you (as a part of role A):

1. You (Your team) have (has) the decision right and the project is successful:

Income = payment from the project alternative you (your team) chose (per person) - costs for the choice of the probability of success (costs are per person)

2. You (Your team) have (has) the decision right and the project is not successful:

Income = payment in case of lack of success (per person) - costs for the choice of the probability of success (costs are per person)

3. You (Your team) do (does) not have the decision right and the project is successful:

Income $=$ payment from the project alternative (per person) role B chose

4. You (Your team) do (does) not have the decision right and the project is not successful:

Income $=$ payment in case of lack of success (per person) 


\section{Detailed procedure for a round on the computer}

$\mathbf{1}^{\text {st }}$ stage: role B's decision

In each round, you as role A first have the decision right. You can also delegate the decision right to role B. Before you decide whether you would like to delegate the decision right to role $\mathrm{B}$, role $\mathrm{B}$ determines in a binding manner - for the case that the decision right is delegated to her - which project alternative and which probability of success that she would like to select. If you actually delegate the decision right to role B, then the decisions role B makes in the first stage will be realized.

You (and your team partner (role A)) will not yet learn which decisions participant B makes in the first stage.

\section{The team decision (just for TEAM treatment)}

In each of the 10 round you and your team partner (together you represent role A) could communicate with each other. That means that team members A1 and A2 could talk within the rounds about their decisions and could exchange preferences. At the end of each round, role A needs to take decisions. A decision is valid, if and only if the decisions of A1 and A2 coincide. So you have to agree on a common decision. Therefore, you can use the chat which is only visible to role $A$ ( $A 1$ and $A 2$ ). The chat is visible and available in all subsections of a round in the lower part of the screen. You can send a message if you write a text in the blue line and press the "Enter" button. You and your partner can see the message immediately afterwards. Both team members A1 and A2 see the same screen but have to enter the decisions individually. At the end of each round both team members see a summary screen with all their decisions. You can still adapt/change your decisions at this stage. It is important that both team members entered the same decisions.

\section{$2^{\text {nd }}$ stage: Who has the decision right?}

You (and your team partner) can decide in each round - after role B has made her decisions whether you would like to delegate the decision right to role B or if you would like to retain this for yourself. In this case, you (and your team partner) do not make the decision directly, but by determining a minimum requirement:

In each round, you (and your team partner) can determine the minimum probability of success that role $B$ must have chosen for you to be willing to delegate the decision right to her. You can choose any minimum requirement between 1 and 100.

Role B has already chosen her probability of success at the time you (and your team partner) determine a minimum requirement. You thus have no opportunity at all to influence the decision that participant $B$ has already made.

Please take note that you (and your team partner) do not know the probability of success that role $\mathrm{B}$ chose when you determine your minimum requirement. 
If the probability of success that role $B$ chooses is greater than the minimum requirement that you (your team) determine (determines), you will delegate the decision right. If the probability of success that role $B$ determines is less than your minimum requirement, you (and your team partner) will retain the decision right.

The graph below clarifies the connection between the minimum requirement you (and your team partner) determine, the probability of success that role B chooses, and the question of who has the decision right?

If, for example, you (and your team partner) decide on a minimum requirement of 45 , this means that you would then like to delegate the decision right to role B if she selects a probability of success of 45 or greater.

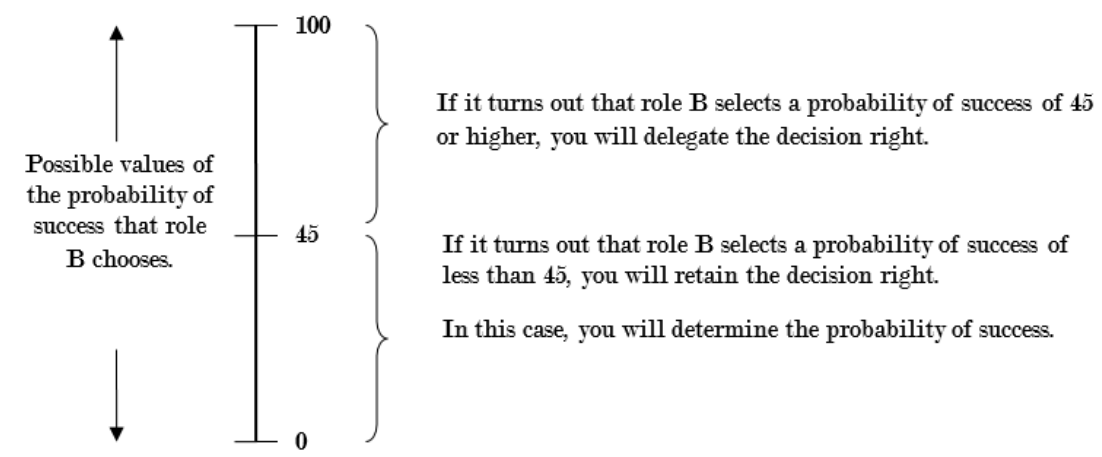

When you (and your team partner) are considering your minimum requirement, you should ask the following:

- Would I (we) want to delegate the decision right if role B selected a probability of success of 1 ? If not, you should then ask:

- Would I (we) want to delegate the decision right if role B selected a probability of success of 2? If not, you should then ask:

- Would I (we) want to delegate the decision right if participant B selected a probability of success of 3? And so on.

Do this until you (your team) reach (reaches) role B's probability of success level, above which you would delegate the decision right. You should determine this as your minimum requirement.

- In the example above, this is the value of 45 . This means that you would just be willing to delegate the decision right if role B selects a probability of success of 45 , but that you would prefer retaining this right at all values of 44 or less.

Further examples:

1. You (Your team) select (selects) a minimum requirement of $\mathbf{7 8 .}$

This means the following: 
- If role B selects a probability of success in stage 1 between 0 and 77, you will not delegate the decision right.

- If role B selects a probability of success in stage 1 between 78 and 100, you will delegate the decision right to her.

2. You (Your team) select (selects) a minimum requirement of 4.

This means the following:

- If role B selects a probability of success in stage 1 between 0 and 3, you will not delegate the decision right.

- If role B selects a probability of success in stage 1 between 4 and 100, you will delegate the decision right to her.

You (and your team partner) make your decision on the minimum requirement for role $\mathrm{B}$ on the screen shown below.

The upper part of the screen always informs you of the payments in the two project alternatives as well as the payment in case of lack of success in the round in question. Furthermore, you will be informed whether the cost schedule on the yellow or the pink information sheet applies. In the middle part of the screen you can enter your minimum requirement. The lower part of the screen contains the chat. Here you can chat with your team partner about your decisions. Here is an example (screenshots for TEAM treatment without chat part):

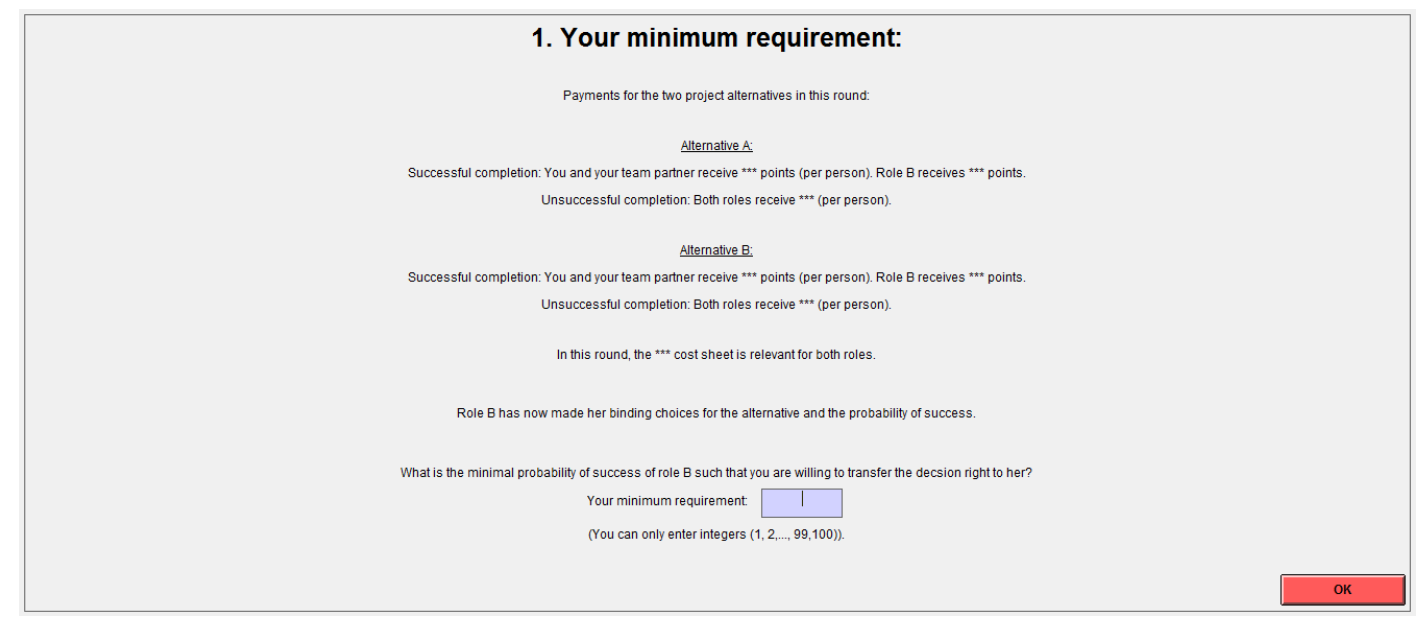

After you have entered your minimum requirement, please click on the OK button to move to the next stage.

\section{$3^{r d}$ stage: Determination of the project alternative}

At the time of the selection of the project alternatives, you (and your team partner) do not yet know whether the probability of success that role B selects is at least as high as your minimum requirement or not. You (and your team partner) therefore do not know whether you delegate 
the decision right or not. For this reason, you (and your team partner) must select the project alternative that you (and your team partner) would like to realize in case you (your team) retain (retains) the decision right. The selection of the project alternative is made on the following screen:

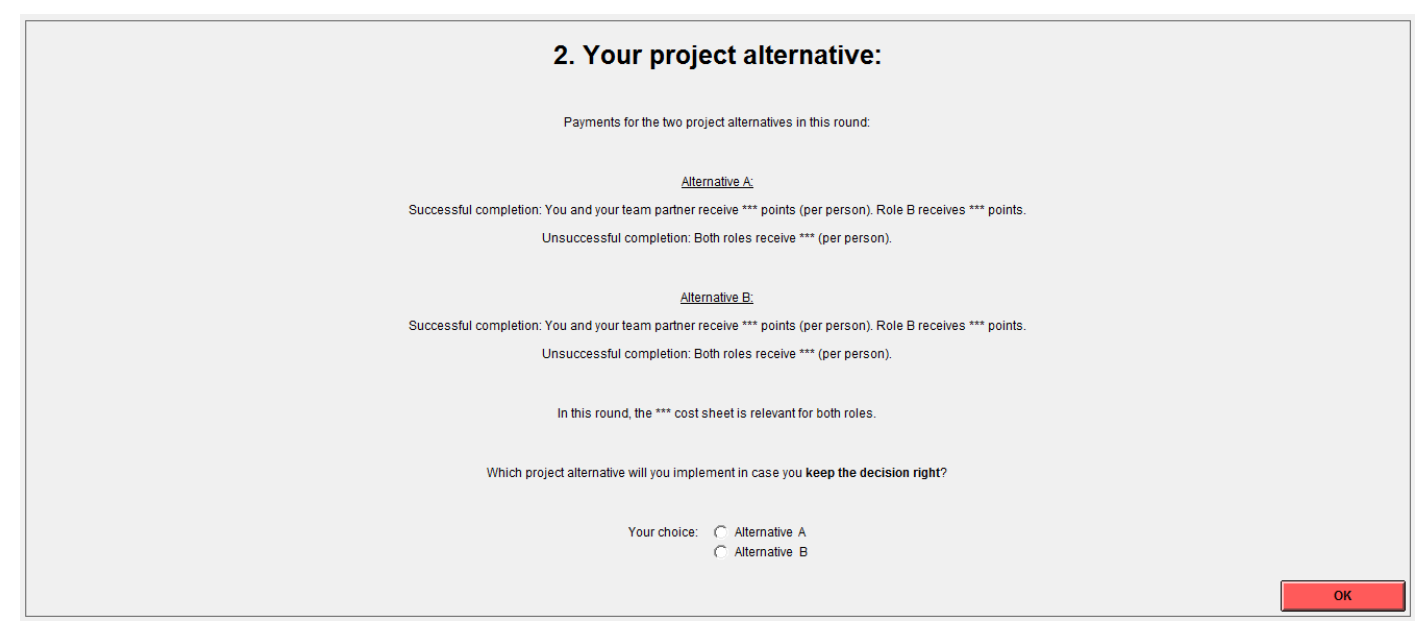

Again, you can use the chat in the lower part of the screen to make common decisions.

After you have chosen the project alternative, please click on the OK button. 


\section{$4^{\text {th }}$ stage: Selection of the probability of success}

Furthermore, you (and your team partner) do not know at the time of your selection of the probability of success whether the decision right will be delegated or if you will retain it. You (and your team partner) must therefore select the probability of success in case you (your team) retain (retains) the decision right. The costs of the probability of success will only be incurred, however, if you (your team) ultimately retain (retains) the decision right. You make your choice of the probability of success on the screen shown on the next page:

\section{Your probability of success:}

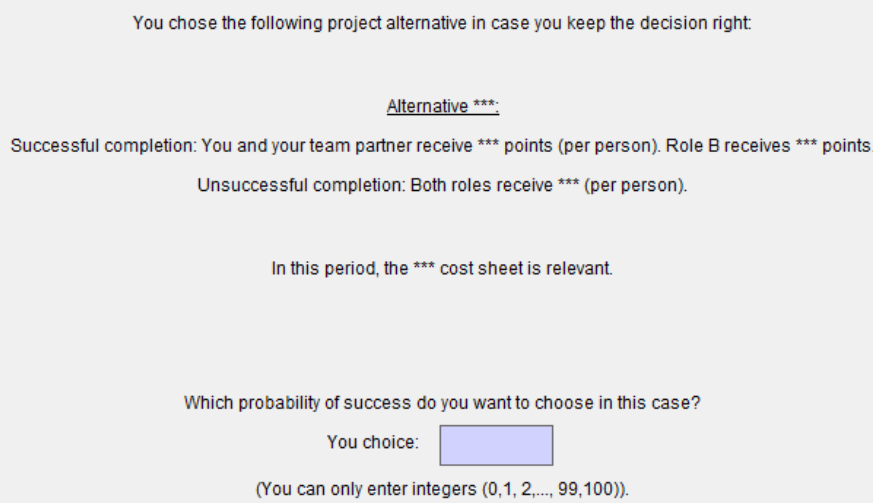

After you have chosen the probability of success, click on the "display costs" button. This will then show the exact costs of the probability of success that you chose. You can then change your probability of success if you wish. You make your final decision with "confirm".

\section{$5^{\text {th }}$ stage: Round summary}

At the end of each round you receive a summary screen of your decision.

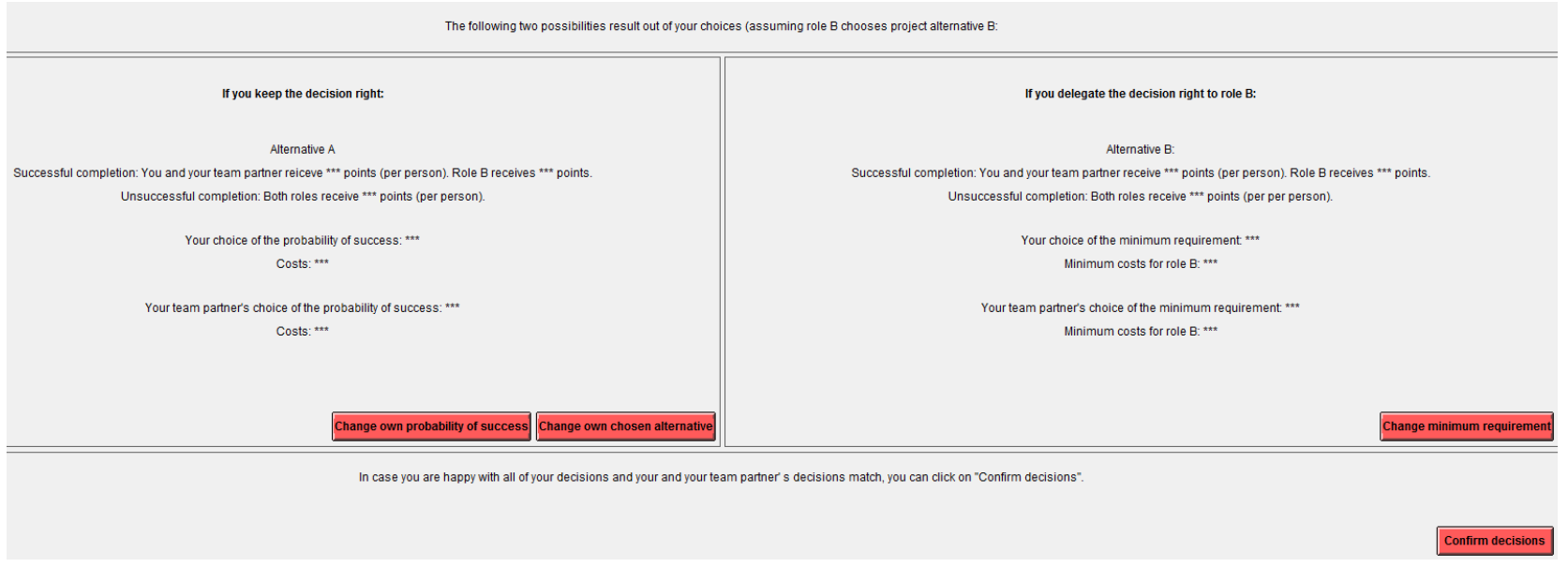


On the left side, you can see your and your team partner's decisions in case you keep the decision right. On the right side, you can see the values if you delegate the decision right to role B. At this stage, you can make changes in your project alternatives, the probability of success and the minimum requirement.

As soon as one of the members of role A (you or your team partner) clicks on "confirm decisions" then it is the final decision and you are not allowed to change anything. If your decisions don't match the decisions of your team partner it is not possible to confirm your decisions. This means that you and your team partner have to enter the same decisions everywhere to be able to start with the next round.

In case you confirmed your decisions, you get to the next round.

$6^{\text {th }}$ stage: Determination of the project success At the end of the study, the computer will randomly determine one of the ten rounds, and the payment that determines your income from this part of the study will be decided for this round based on your (and your partner's) decision and that of the role B assigned to you in this period. As you do not know which round the computer will randomly determine, you (and your team partner) should consider your decisions in each round very carefully.

a) The computer will first randomly determine which round will be selected for payment.

b) It will then examine whether the role B randomly assigned to you in this round chose a probability of success that is at least as large as your minimum requirement.

- If the minimum requirement is fulfilled, you (your team) will delegate the decision right.

- If the minimum requirement is not fulfilled, you (your team) will retain the decision right.

If you retain (your team retains) the decision right, you (or your team partner) can determine the project success yourself by rolling the dice. You will do this at your desk, under supervision of the head of the study. You can decide within your team who should roll the dice. The result is entered on the following screen: 


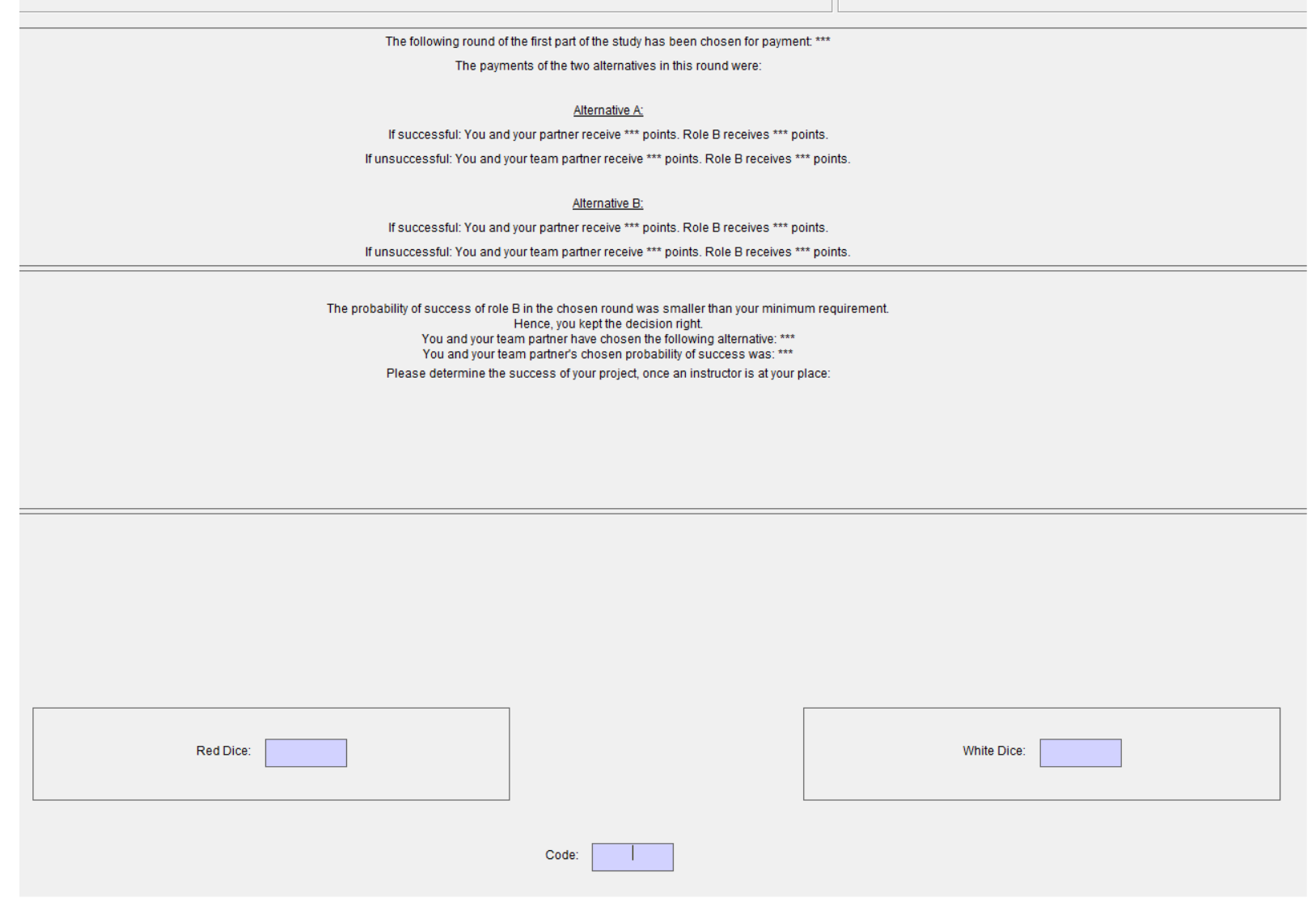

You can roll the dice yourself, but the entry of the result and the code (necessary in order to press the "continue" button) must be done by the head of the study.

Do you have questions about the first part of the study? Please raise your hand. We will come to your desk. If you do not have any questions, please answer the control questions on the next pages. You have to enter the correct answers on the screen later. 


\section{Test questions}

\section{Role A and Part 1}

Please answer the following test questions. Please contact the head of the study if you have any questions.

1. Assume you (your team) determined a minimum requirement of 85 .

(a) If role B selects a probability of success of 80 , who has the decision right in this round? Role

(b) If role B selects a probability of success of 90 , who has the decision right in this round? Role ........

2. Assume you (your team) determined a minimum requirement of 55.

(a) If role B selects a probability of success of 50, who has the decision right in this round? Role

(b) If role B selects a probability of success of 60 , who has the decision right in this round? Role ........

3. Assume role B chose a probability of success of 3 .

(a) If you (your team) specify (specifies) a minimum requirement of 1 , who has the decision right in this round? Role

(b) What is the probability that the project will then be successful?

(c) If, however, you (your team) specify (specifies) a minimum requirement of 4 , who has the decision right in this round? Role .........

4. Assume role B chose a probability of success of 90 .

(a) If you (your team) specify (specifies) a minimum requirement of 85, who has the decision right in this round? Role

(b) What is the probability that the project will then be successful?

(c) If, however, you (your team) specify (specifies) a minimum requirement of 95, who has the decision right in this round? Role ........ 
5. Assume that you (your team) retained the decision right and chose a probability of success of 54. The cost schedule on yellow information sheet applies in this round. Assume further that you roll an 8 with the red die and a 2 with the white one.

(a) How high are your costs (per person)? .........

(b) Would the project have been successful?

The following payments apply for the project:

\begin{tabular}{|c|c|c|c|}
\hline & & Your payment (per person) & Payment to role B \\
\hline \multirow{2}{*}{ Successful completion } & Alternative A & 200 & 150 \\
\cline { 2 - 4 } & Alternative B & 150 & 200 \\
\hline \multicolumn{2}{|r|}{ If unsuccessful } & 100 & 100 \\
\hline
\end{tabular}

Assume you (your team) chose (chose) project alternative A.

(a) How high would your income (per person) be?

(b) How high would role B's income be?

Now assume that you (your team) chose (chose) a probability of success of 24. Assume further that you roll a 1 with the red die and a 5 with the white one. The cost schedule on yellow information sheet applies in this round. You (your team) again chose (chose) project alternative $\mathrm{A}$.

(a) How high are your costs (per person)? .........

(b) Would the project have been successful?

(c) How high would your income (per person) be?

(d) How high would role B's income be? 
6. Assume that you (your team) delegated the decision right. Role B selected project alternative $B$ and chose a probability of success of 48 . The cost schedule on pink information sheet applies in this round.

The following payments apply for the project:

\begin{tabular}{|c|c|c|c|}
\hline & & $\begin{array}{c}\text { Your payment } \\
\text { (per person) }\end{array}$ & Payment to role B \\
\hline \multirow{2}{*}{ Successful completion } & Alternative A & 200 & 150 \\
\cline { 2 - 4 } & Alternative B & 150 & 200 \\
\hline \multicolumn{2}{|r|}{ If unsuccessful } & 100 & 100 \\
\hline
\end{tabular}

Assume further that role B rolls a 5 with the red die and a 7 with the white one.

(a) Would the project have been successful?

(b) How high would your income (per person) be?

(c) How high would role B's income be?

Now assume role B rolls a 3 with the red die and a 9 with the white one.

(a) Would the project have been successful?

(b) How high would your income (per person) be?

(c) How high would role B's income be? 


\section{Instructions for role B}

Welcome to today's experiment. You receive $€ 4$ as a show-up fee. During the experiment you will be asked to make decisions and so will the other participants. Your decisions, as well as the decisions of the other participants, will determine your monetary payoff. Therefore, it is important that you carefully read the instructions. If you have any questions during the experiment, please raise your hand and one of the experimenters will come to assist you.

Please do not communicate with other participants before the end of the experiment. Please switch off your mobile phone. In addition, we want to point out that you are only allowed to use the computer functions that are intended for the course of the study. If you violate these rules, you will be immediately excluded from the experiment and all payments. At the end of the experiment we will pay you in cash $€ 4$ as a show-up fee and the money you've earned during the experiment. Your income in the experiment will be in "points". At the end of the experiment, tokens will be converted into euro at an exchange rate of

\section{Points $=2$ Euros}

This study consists of three parts:

1. The first part of the study lasts 10 rounds. You will be paired with a different role A in each of the 10 rounds of the study. You can complete a project with the role A who is paired with you in each round. You will find detailed explanations about this first part of the study on the following pages.

2. You will receive exact instructions about the second part as soon as the first part is completed.

3. The third part of the study is very short, and you will receive instructions on screen as soon as the second part is completed. 


\section{General information about the first part of the study}

There are two types of roles in the first part of the study: role A (two persons) and role B. You are role $B$.

There are ten rounds. You will be paird with a different role A in each round. A project can be completed in each round. A successful competion of the project will lead to a positive payment for roles A and B.

\section{The decision right}

In each period, either you or role A has the decision right. The role with the decision right can make two decisions:

\section{Which alternative of the project - A or B - will be completed?}

Role A receives the larger share of the project income in alternative $\mathrm{A}$, and role $\mathrm{B}$ receives the larger share of the project income in alternative B. (It is possible that roles A and B will receive the same amounts in some rounds.)

\section{What is the probability that the project will be successful?}

The determination of the probability of success is associated with costs for the role with the decision right. The higher the probability of success, the higher the costs.

\section{Payment of the project}

The payments that result from completion of the project vary from round to round. You will be infromed of the payments at the beginning of each round.

Example: The payments from the project in a round: In case of success, you will receive 200 points in alternative B and role A will receive 150 points. Role A will reiceve 200 points in case of success in alternative A and you will recieve 150 points. If the project is unsuccessful, both role $\mathrm{A}$ and role $\mathrm{B}$ receive 100 points.

\begin{tabular}{|c|c|c|c|}
\hline & & $\begin{array}{c}\text { Payment to } \\
\text { role A (per person) }\end{array}$ & Your payment \\
\hline \multirow{2}{*}{ Successful completion } & Alternative A & 200 & 150 \\
\cline { 2 - 4 } & Alternative B & 150 & 200 \\
\hline \multicolumn{2}{|r|}{ If unsuccessful } & 100 & 100 \\
\hline
\end{tabular}




\section{The probability of success}

If you have the decision right, then you can determine the probability with which the chosen project alternative - A or B - will be successful.

\section{How is the probability of success determined?}

The prbability of success is a number between 0 and 100 that can be chosen freely.

$$
\mathbf{0} \leq \text { probability of success } \leq \mathbf{1 0 0}
$$

A probability of success of 0 means that the project will never be successful. A probability of success of 100 means that the project will always be successful. For all values in between, a project might be successful or it might not be so. A value of 50 means that a project has a $50 \%$ chance of being successful.

If the project is successful, roles $A$ and $B$ will be paid out in accordance to the chosen alternative (in the example above, 150 or 200 points). If the project is not successful, both participants will receive a lower payment independent of the chosen alternative (in the example above, 100 points each).

\section{The costs of the choice of the probability of success}

The higher the probability of success you choose, the higher are your costs. Two information sheets (yellow and pink) are at your desk; they show you both in a table and in a graph how high the costs are for the various possible probabilities of success. You will be informed in each round whether the costs on the yellow or on the pink sheet apply. You can also always have the computer show you the costs on the monitor while choosing the probability of success.

\section{A roll of the dice determines whether the project is successful}

The role with the decision right can roll two dice at his or her desk - they are red and white (and show the numbers from 0 to 9). The red die determines the first digit and the white the second digit. This results in a number between 1 and 100 (two zeros are valued as 100). If the number rolled is smaller than or equal to the chosen probability of success, the project is successful. If the number rolled is larger, the project is not successful. The greater the probability of success that you choose, the greater the possibility that the number rolled is smaller than the chosen number, i.e., that the project is successful. 
Examples:

1. Example: You choose a probability of success of 15, i.e., $15 \%$

This means the following:

- If - through rolling the red and the white dice - a smaller or equal number results, i.e. a number between 1 and 15 (= 15 of 100 possibilities), the project is successful.

- If the number is greater than 15 (= 16 to 100 , or 85 possibilities) results, then the project is not successful.

2. Example: You choose $\mathbf{8 0}$ as the probability of success, i.e., a probability of success of $80 \%$.

This means the following:

- If - through rolling the red and the white dice - a number between 1 and 80 (= 80 of 100 possibilities), the project is successful.

- If the number is greater than 80 (= 81 to 100 , or 20 possibilities) results, then the project is not successful.

- Assume that you roll the number 9 with the red die and a 3 with the white one. This results in the number 93.

In this case, neither example would have been successful (the number rolled is, in both cases, larger than the chosen probability of success).

- Assume that you roll the number 5 with the red die and a 4 with the white one. This results in the number 54 .

In this case, the project in the first example would not have been successful (the number rolled is larger than 15), but the project in the second example would have been successful (the number rolled is less than 80).

- Assume that you roll the number 0 with the red die and a 3 with the white one. This results in the number 03.

In this case, the project would have been successful in both examples (the number rolled is less than the probability of success chosen in each example). 


\section{The income}

The incomes of roles A and B consist of the following two parts:

- Payment from the chosen project alternative if the project is successful. If the project is not successful, both roles receive a lower payment that is independent of the project alternative.

- The costs for the probability of success will be deducted from the corresponding payment for the role with the decision right.

The following four possibilites thus result for you:

1. You have the decision right and the project is successful:

Income = payment from the project alternative you chose - costs for the choice of the probability of success

2. You have the decision right and the project is not successful:

Income $=$ payment in case of lack of success - costs for the choice of the probability of success

3. You do not have the decision right and the project is successful:

Income = payment from the project alternative role A chose

4. You do not have the decision right and the project is not successful:

Income = payment in case of lack of success 


\section{Detailed procedure for a round on the computer}

\section{$\mathbf{1}^{\text {st }}$ stage: Your decision as role B}

In each round, role $\mathrm{A}$ first has the decision right. Role A can also delegate the decision right to you as role $\mathrm{B}$. Before role A decides whether he would like to delegate the decision right to you, you determine in a binding manner - for the case that the decision right is delegated to you - which project alternative and which probability of success that you would like to select.

If role A actually delegates the decision right to you, then the decisions you make in the first stage will be realized.

You should therefore carefully consider which probability of success and which project alternative you would like to choose, even though you do not yet know whether your will have the decision right.

\section{Role A will not yet learn which decisions you as role B make in the first stage.}

You will make your choices of project alternative on the following screen:

The upper part of the screen informs you of the payments for the two project alternatives as well as the payment in case of lack of success in the round in question. You will also be informed whether the cost schedule on the yellow or the pink information sheet applies. You can choose the project alternative in the lower part of the screen.

Here is an example:

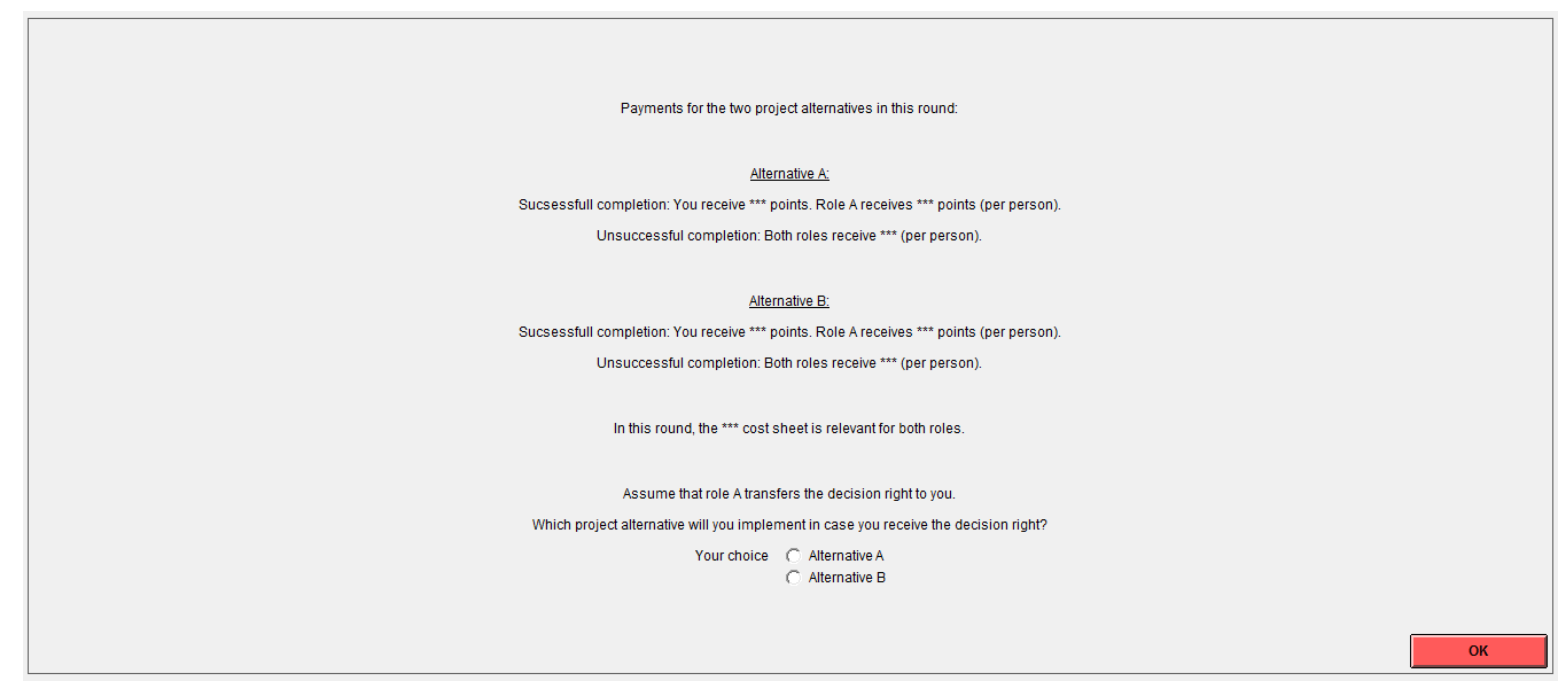

After you have chosen the project alternative, please click on the OK button. 
You make your selection of the probability of success on the screen shown below:

Here is an example:

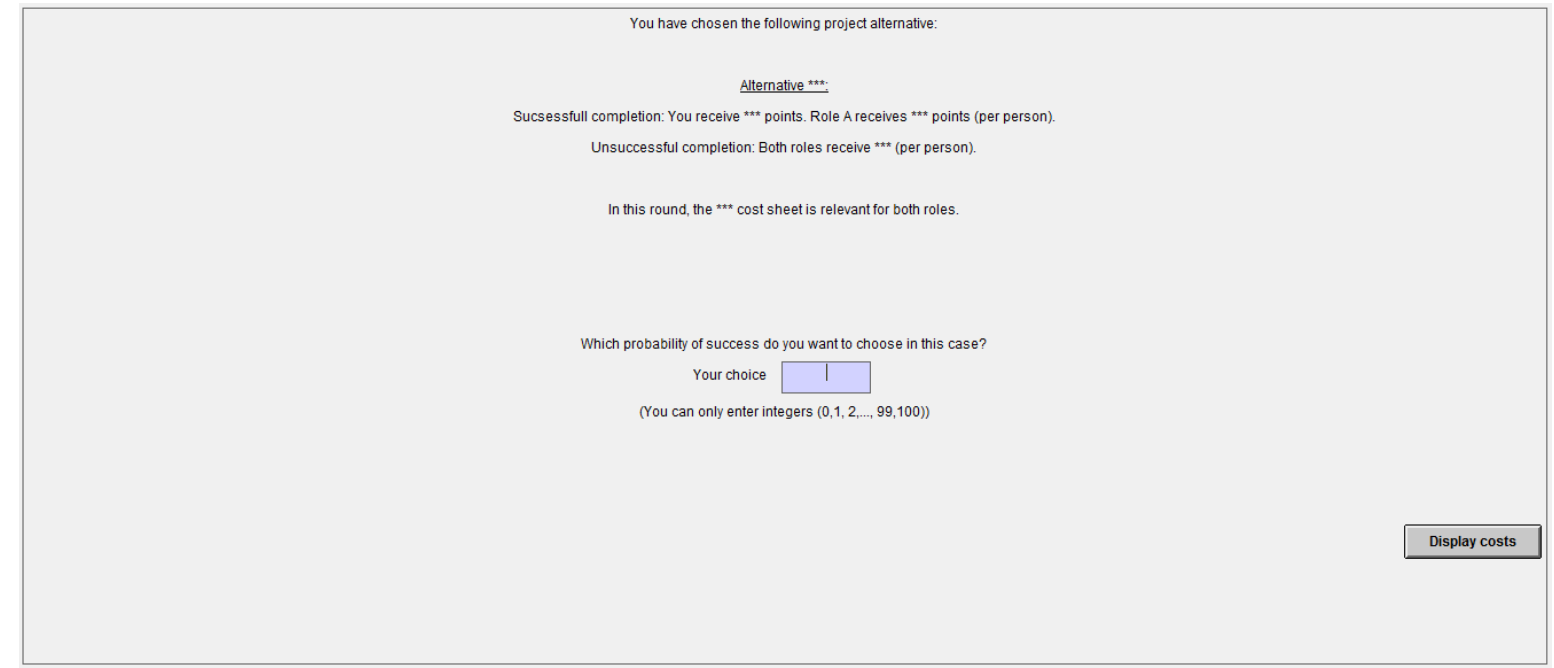

After you have chosen the probability of success, click on the "display costs" button. This will then show the exact costs of the probability of success that you chose. You can then change your probability of success if you wish. You make your final decision with "confirm".

Please take note that the costs for the choice of probability of success only apply if the decision right is actually delegated to you.

$2^{\text {nd }}$ stage: Who has the decision right?

Role A can decide in each round - after you as role B have made your decisions - whether she would like to delegate the decision right to you or if she would like to retain this for herself.

In this case, role A does not make the decision directly, but by determining a minimum requirement:

In each round, role $A$ can determine the minimum probability of success that role $B$ must have chosen for her to be willing to delegate the decision right to role $B$.

Please take note that role A does not know the probability of success that you chose when she determines her minimum requirement.

If the probability of success that you choose is greater than the minimum requirement that role A determines, role A will delegate the decision right. If the probability of success that you determine is less than the minimum requirement, role A will retain the decision right.

$3^{r d}$ stage: Selection of project and determination of the probability of success by role A

If role A retains the decision right, she selects a project and determines a probability of success.

$4^{\text {th }}$ stage: Determination of the project success 
At the end of the study, the computer will randomly determine one of the ten rounds, and the payment that determines your income from this part of the study will be decided for this round based on your decision and that of the role A assigned to you in this period. As you do not know which round the computer will randomly determine, you should consider your decisions in each round very carefully.

a) The computer will first randomly determine which round will be selected for payment.

b) It will then examine whether you chose a probability of success that is at least as large as the minimum requirement of the role A who was randomly assigned to you in this round.

- If the minimum requirement is fulfilled, role A will delegate the decision right to you.

- If the minimum requirement is not fulfilled, role A will retain the decision right.

If you were delegated the decision right, you can determine the project success yourself by rolling the dice. You will do this at your desk, under supervision of the head of the study. The result is entered on the following screen:

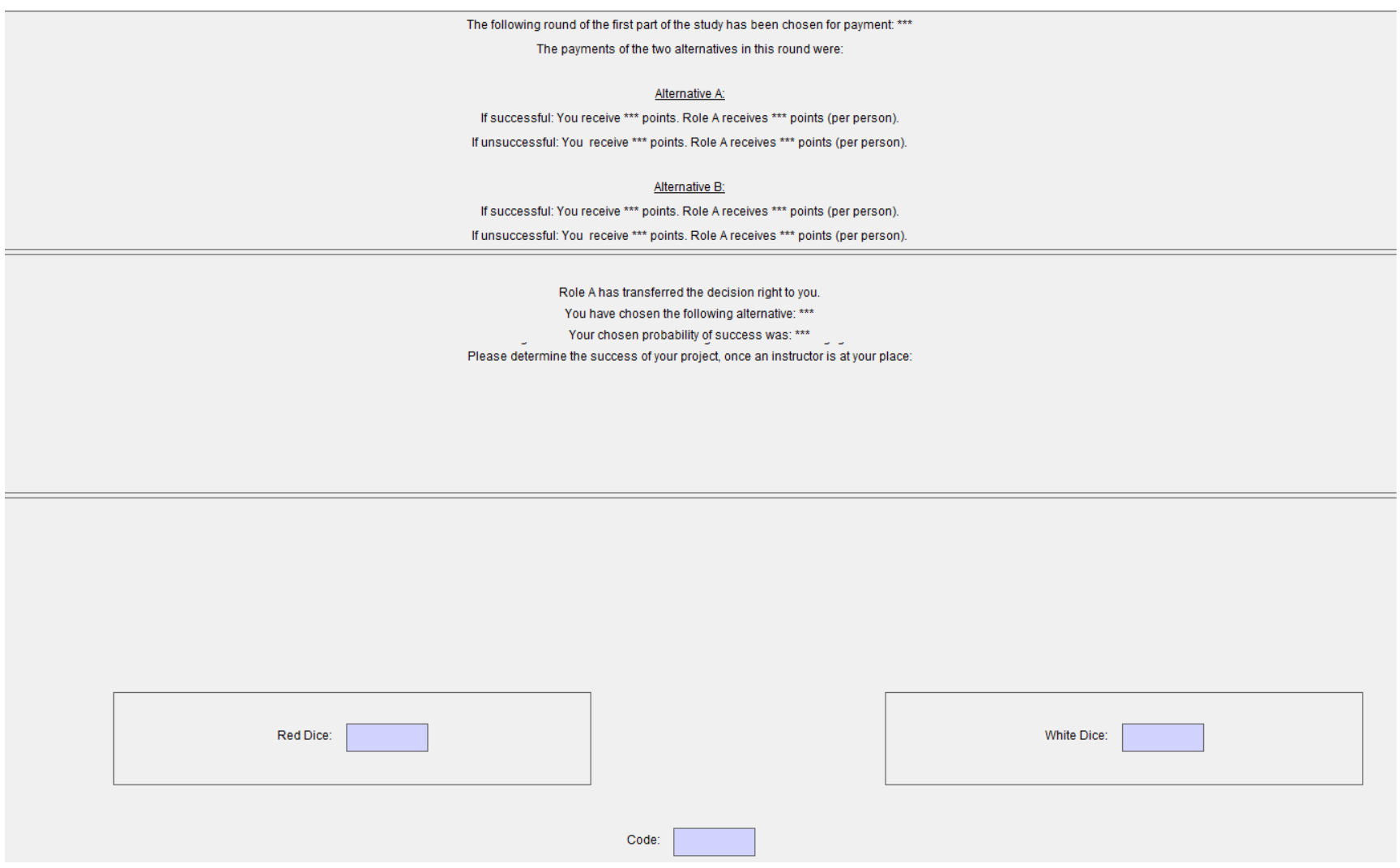

You can roll the dice yourself, but the entry of the result and the code (necessary in order to press the "continue" button) must be done by the head of the study.

Do you have questions about the first part of the study? Please raise your hand. We will come 
to your desk. If you do not have any questions, please answer the control questions on the next pages. You have to enter the correct answers on the screen later. 


\section{Test questions}

\section{Role B and Part 1}

Please answer the following test questions. Please contact the head of the study if you have any questions.

1. Assume you chose a probability of success of 3 .

(a) If role A specifies a minimum requirement of 1 , who has the decision right in this round? Role

(b) What is the probability that the project will then be successful?

(c) If, however, role A specifies a minimum requirement of 4, who has the decision right in this round?

2. Assume you chose a probability of success of 90 .

(a) If role A specifies a minimum requirement of 85 , who has the decision right in this round? Role

(b) What is the probability that the project will then be successful?

(c) If, however, role A specifies a minimum requirement of 95 , who has the decision right in this round?

3. Assume that you received the decision right and chose a probability of success of 54 . The cost schedule on yellow information sheet applies in this round. Assume further that you roll an 8 with the red die and a 2 with the white one.

(a) How high are your costs?

(b) Would the project have been successful?

The following payments apply for the project:

\begin{tabular}{|c|c|c|c|}
\hline & & $\begin{array}{c}\text { Payment to } \\
\text { role A (per person) }\end{array}$ & Your payment \\
\hline \multirow{2}{*}{ Successful completion } & Alternative A & 200 & 150 \\
\cline { 2 - 4 } & Alternative B & 150 & 200 \\
\hline \multicolumn{2}{|r|}{ If unsuccessful } & 100 & 100 \\
\hline
\end{tabular}

Assume you chose project alternative B.

(a) How high would your income be?

(b) How high would role A's income (per person) be? 
Now assume that you received the decision right and chose a probability of success of 24. Assume further that you roll a 1 with the red die and a 5 with the white one. The cost schedule on yellow information sheet applies in this round. You again chose project alternative B.

(a) How high are your costs?

(b) Would the project have been successful?

(c) How high would your income be?

(d) How high would role A's income (per person) be? 


\section{A.5.2 Instructions - Part 2}

\section{Second part of the experiment - Instructions 21}

There are 20 rounds in this part of the study. You are randomly paired with another participant in the study in each round. (You and your permanent partner from the previous part (role A) are randomly paired with another participant in the study in each round.) The exchange rate of $\mathbf{1 0 0}$ points $=\mathbf{2}$ Euro still applies.

In each round, you (your team) must decide between a guaranteed payment and a variable payment. Your decision also determines the payment of the other participant randomly assigned to you.

An example:

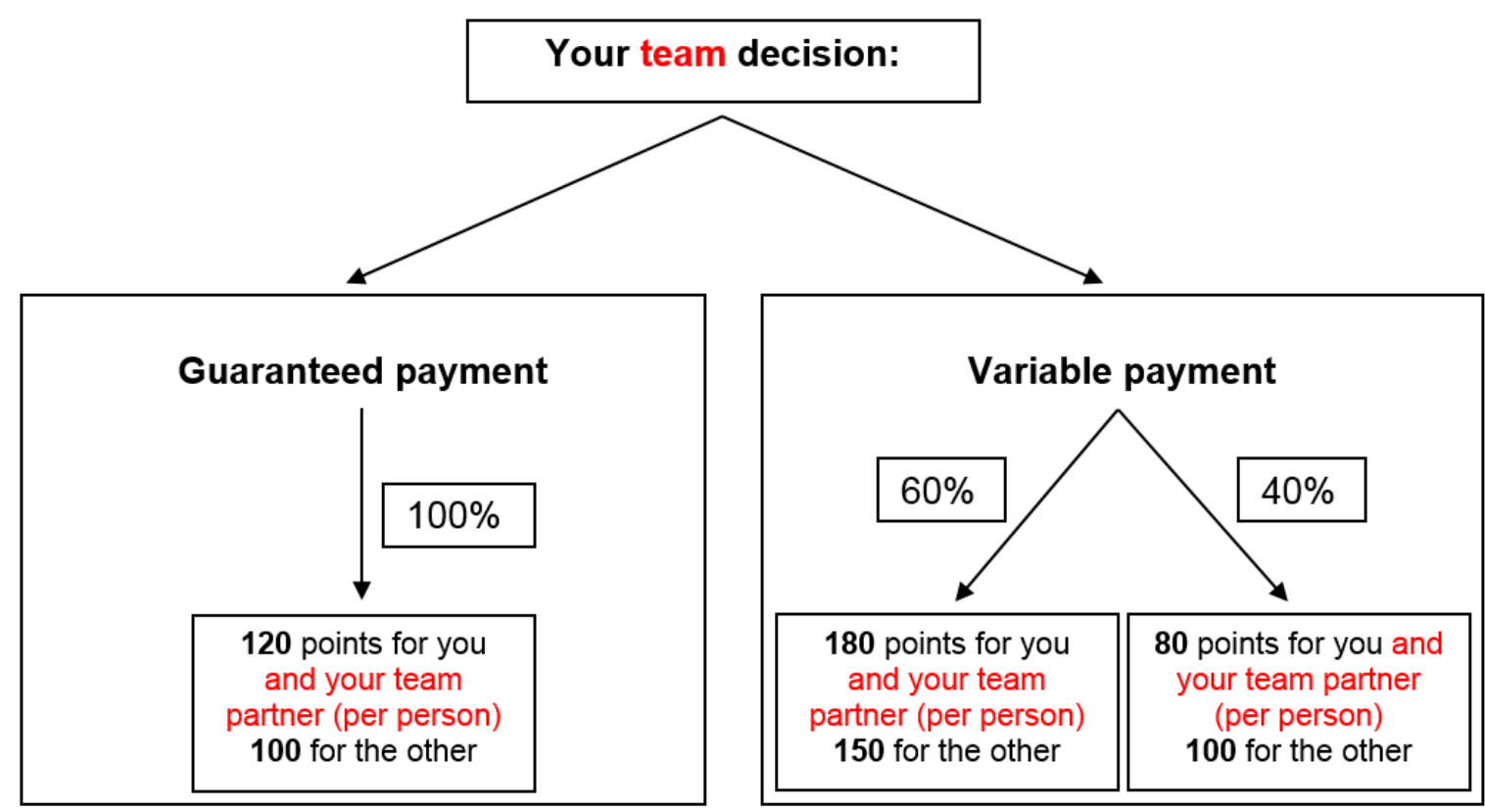

If, in the example above, you decide for the guaranteed payment, you will receive 120 points (per person) and the other, randomly assigned participant will receive 100 points.

If you (your team) opt for the variable payment, there is a $60 \%$ probability that you will receive a payment of 180 points (per person) and the other participant will receive 150 points. There is a $40 \%$ probability that you will receive 80 points (per person) and the other participant will receive 100 points.

You (and your team partner) make a decision in each of the 20 rounds between a guaranteed payment and a variable payment. The payments and the probabilities in case of the variable payment differ in each round.

\footnotetext{
${ }^{21}$ Same instructions for role A and role B, but again modifications for teams in red.
} 
How can you (and your team partner) make your decision between the guaranteed and the variable payment in each round?

When you (and your team partner) make your decision in a round between the guaranteed and the variable payment, you (and your team partner) do not yet know the amount of your guaranteed payment (per person). You (and your team partner) cannot therefore make a direct decision between the guaranteed and the variable payment, rather, you (and your team partner) must indicate how high your guaranteed payment (per person) must be for you to opt for the guaranteed payment instead of the variable payment.

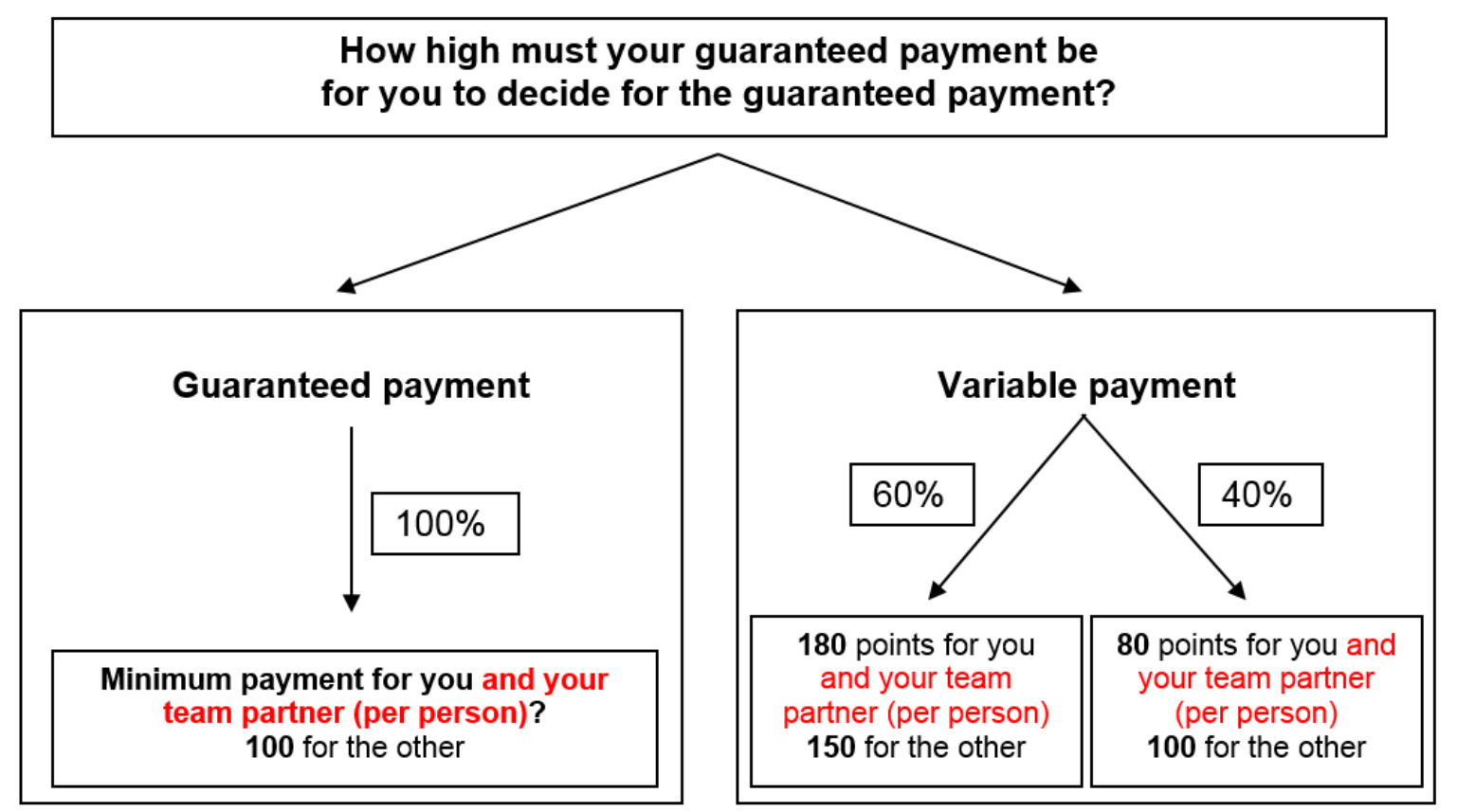

You will be informed of the guaranteed payment for the other participant, the variable payments for you (your team (per person)) and the other participant, and the probabilities in case of the variable payments in each round.

After you (and your team partner) have indicated the minimum payment that would make you (your team) decide for the guaranteed payment in a round, your actual guaranteed payment in this round will be notified to you. The decision between the guaranteed payment and the variable payment is then realized as follows:

- If the actual guaranteed payment is less than the minimum payment you (your team) indicate (indicates), the variable payment determines your income (your team income) and that of the other participant. 
- If the actual guaranteed payment is greater than or equal to the minimum payment you (your team) indicate (indicates), you (and your team partner) will receive the actual guaranteed payment and the other participant will also receive the secure payment shown on the screen (100 points in the example above).

The possible values of your guaranteed (team) payment lie between both of your variable (team) payments (per person) (in the example above, between 80 and 180 points). Any integer value in this interval $(80,81,82,83, \ldots, 180)$ is equally probable. The minimum payment you (your team) indicate (indicates) can also be any integer value between both of your variable payments.

The graph below again clarifies the connection between the minimum payment you (your team) determine (determines), the amount of the actual guaranteed payment, and your (team) decision between the guaranteed and the variable payment:

If, for example, you (and your team partner) indicate a minimum payment of 127 , this means that you prefer any guaranteed payment between 127 and 180 points to the variable payment.

You will be informed of the exact amount of your actual guaranteed payment (per person) after you determine your minimum payment.

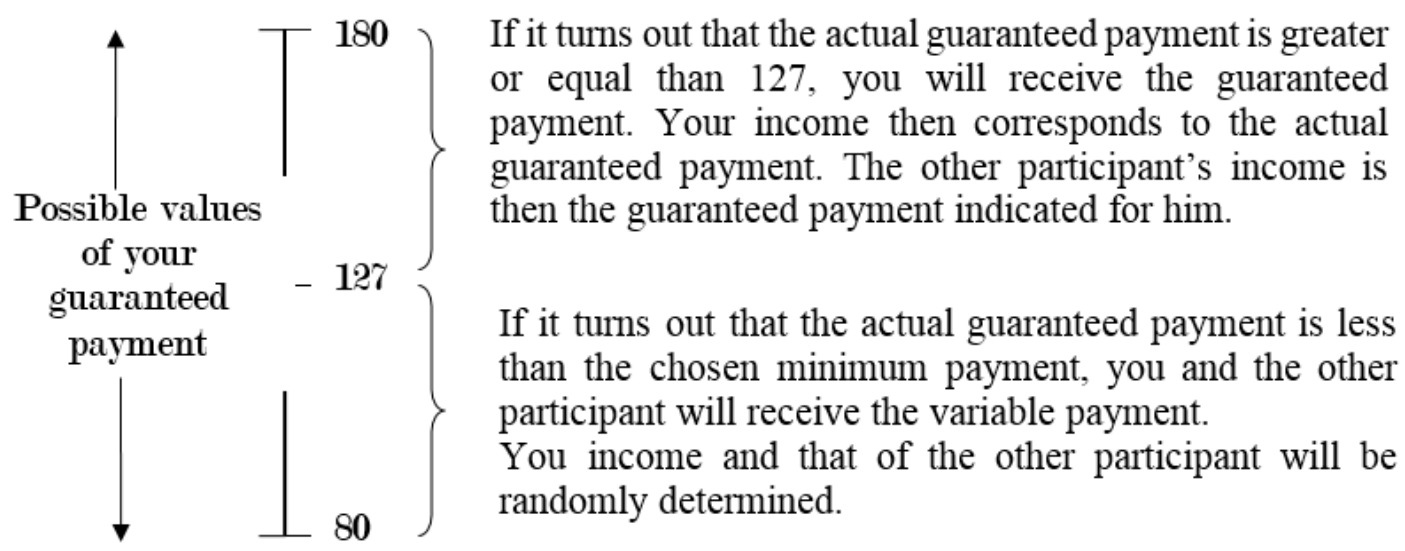

When you (and your team partner) consider your minimum (team) payment (per person), then you should (assuming the numbers from the example above) ask the following questions:

- Would I (we) prefer a guaranteed payment amounting to 180 (per person) points to the variable payment? If yes, then you should ask:

- Would I (we) prefer a guaranteed payment amounting to 179 (per person) points to the variable payment? If yes, then you should ask:

- Would I (we) prefer a guaranteed payment amounting to 178 (per person) points to the variable payment? If yes, then you should ask: 
Continue this way until you (your team) reach (reaches) a point amount for the guaranteed payment where you (and your team partner) would just prefer the guaranteed payment. You (Your team) should then enter this point amount as the minimum payment.

The value is 127 in the example above. This means that you (your team) just prefer (prefers) the guaranteed payment instead of the variable payment in case of a guaranteed payment of 127 (per person), but at a lower point amount of 126 (per person) (and at all values below this), you would prefer the variable payment. The income:

\section{If the actual guaranteed payment is at least as high as the minimum payment you (your team) indicate (indicates):}

You (and your team partner) will receive the actual guaranteed payment. The other participant will receive the guaranteed payment indicated for him.

If the actual guaranteed payment is less than the minimum payment you (your team) indicate (indicates):

The choice between the indicated variable payments for you (your team (per person)) and the other participant

will be made randomly with the probabilities that are given.

The computer will randomly determine 2 of the 20 rounds at the end of the study.

In each of the randomly chosen rounds, the minimum payment (per person) you indicate will be compared with the actual guaranteed payment (per person). If the actual guaranteed payment is greater than or equal to the minimum payment you indicate, you will receive the guaranteed payment. If the actual guaranteed payment is less than the minimum payment you (your team) indicate (indicates), a cast of the dice will determine which of the variable payments you and the other participant each receive.

As you (your team) do (does) not know which 2 of the 20 rounds the computer will randomly determine, you should consider your (team) decisions in each round very carefully. 


\section{Procedure on the computer}

The team decision follows the same rules as in part 1 of this experiment. Both team members $\mathrm{A} 1$ and A2 have to make the same decisions. You can communicate via the free text chat again.

1. You enter your decision about the guaranteed payment that you must receive as a minimum in order to make you prefer the guaranteed payment over the variable payment in each round on the computer screen below.

Here is an example:
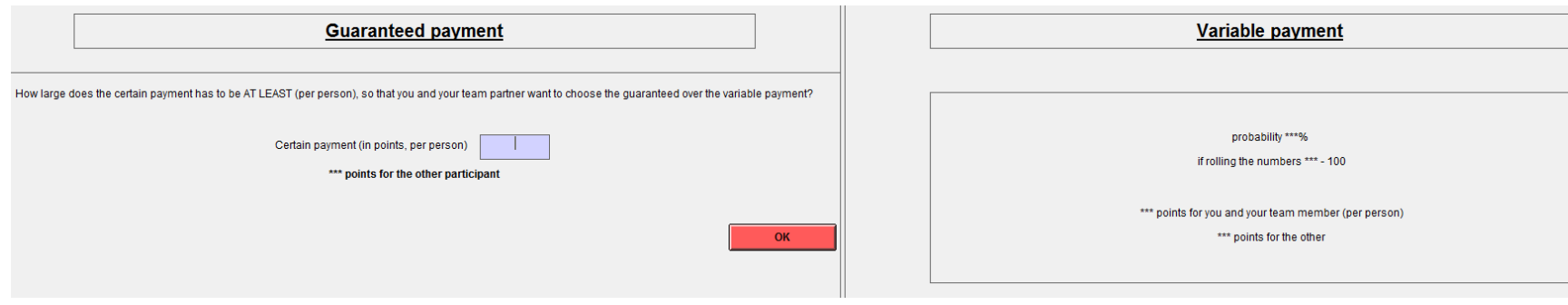

You see the variable payments for you (your team) and for the other randomly chosen participant on the right side of the screen. You will also see the probability with which the payments will occur. This information varies in each of the 20 rounds. You enter your minimum payment (per person) on the left side of the screen. The minimum payment indicates which guaranteed payment you (your team (per person)) must receive in minimum to make it so that you prefer the guaranteed payment to the variable payment. When you have made your entry, please click on the OK button. You can change your entry until you click on the OK button.

A confirmation of your entry is only possible, if the entries of A1 and A2 are identical. 
2. If the minimum payment you (your team) indicate (indicates) lies under the actual guaranteed payment in one of the chosen rounds, a cast of the dice will determine which of the variable payments you (your team) and the other participant will receive. Casting the dice works in exactly the same way as in the first part of the study. The head of the study will enter the numbers that are cast in the screen below.

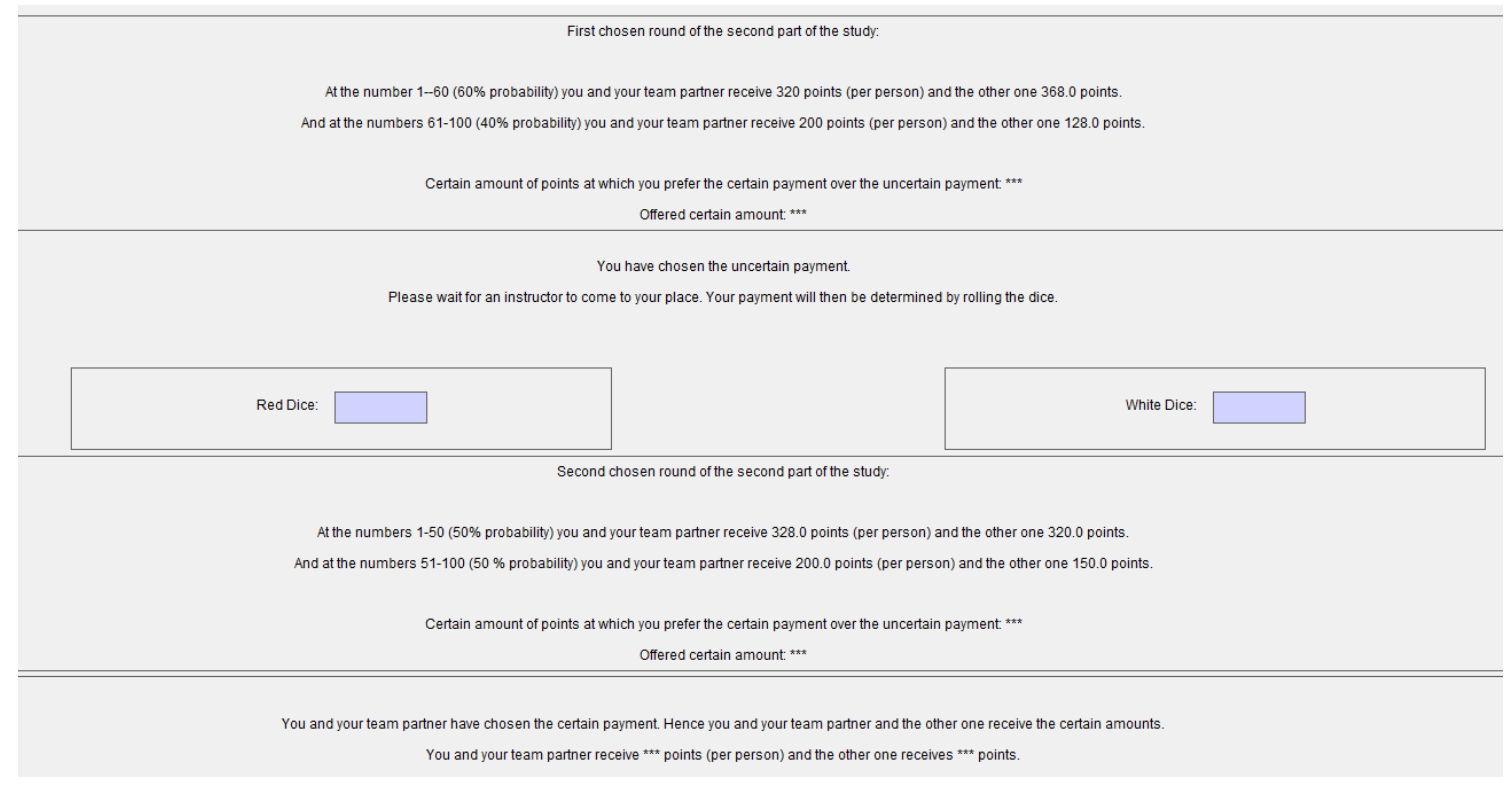

Do you have questions about the second part of the study? Please raise your hand. We will come to your desk. If you do not have any questions, please answer the control questions on the next pages. You have to enter the correct answers on the screen later. 


\section{Test questions}

Part 2

Assume that the following payments and probabilities apply for the case of the variable payment.
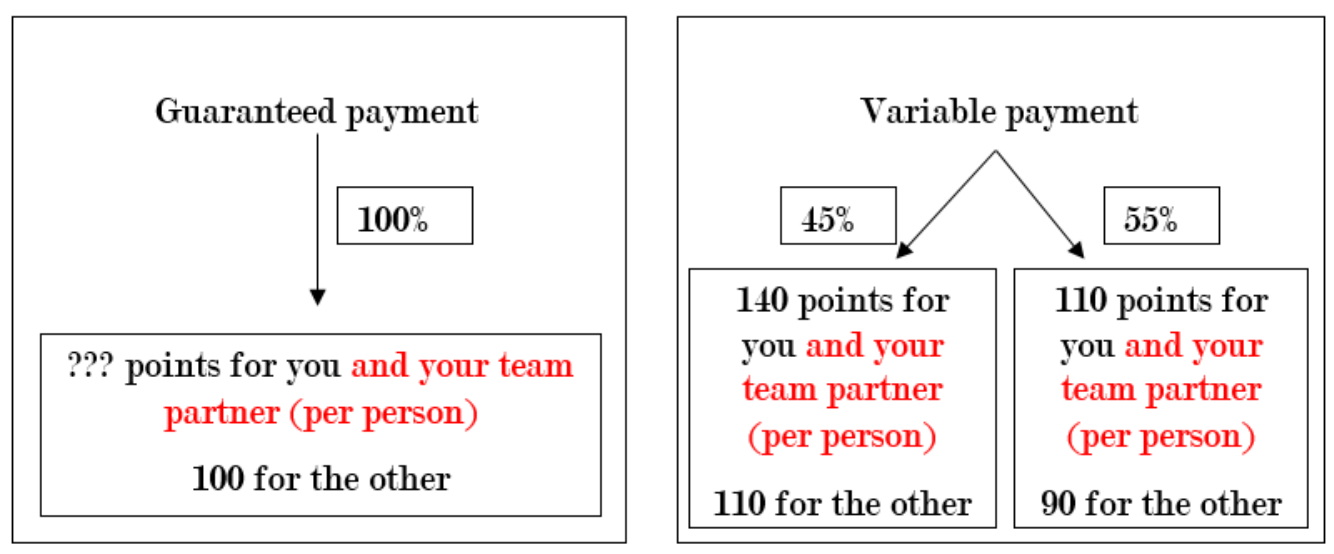

1. Assume you (your team) specify (specifies) a minimum payment of $\mathbf{1 2 0}$.

(a) Assume the actual guaranteed payment is 128 .

How high is your payment in this round (per person)? ....

How high is the other participant's payment in this round? ....

(b) Assume the actual guaranteed payment is 117.

How high is your payment in this round (per person)? ....

How high is the other participant's payment in this round? ....

2. Assume you (your team) specify (specifies) a minimum payment of 135.

(a) Assume the actual guaranteed payment is 128 .

How high is your payment in this round (per person)? ....

How high is the other participant's payment in this round? ....

(b) Assume the actual guaranteed payment is 113.

How high is your payment in this round (per person)? ....

How high is the other participant's payment in this round? ....

3. Assume you (your team) specify (specifies) a minimum payment of 115 .

(a) Assume the actual guaranteed payment is 128 .

How high is your payment in this round (per person)? ....

How high is the other participant's payment in this round? ....

(b) Assume the actual guaranteed payment is 135.

How high is your payment in this round (per person)? ....

How high is the other participant's payment in this round? ....

Please raise your hand when you have answered the questions. We will come to you at your desk. 


\section{A.5.3 Instructions - Part 3}

\section{Additional information 22}

The computer will now randomly determine the round that is relevant for your (team) payments from the first part of the study. If you (and your team partner) have the decision right in the chosen round, you can determine the project success by rolling the dice.

We would like to know from you (as a team) whether it is worth points to roll the dice yourself and not to let another person roll the dice. (This only involves rolling the dice and not the selection of the probability of success or the project alternative.)

You (Your team) will now receive another 30 points. You can use some or all of these 30 points to purchase the right "to roll the dice yourself". If you do not purchase this right, the head of the study will roll the dice for you (your team). The head of the study will roll the dice fairly using a cup for dice, i.e., exactly as you would have done it. If you purchase the right to roll the dice, then you do so yourself.

We will pose the following question on the screen:

Are you willing to pay to be able to roll the dice yourself? Yes or No?

\section{Team decision:}

You are again matched with your fixed partner. The team decision works as in the previous rounds. You can communicate via the free text chat and have to reach a common decision.

If you (your team) click (clicks) on "yes" on the computer, we will then ask the maximum number of points you are willing to pay to be able to roll the dice yourself (for the case that you retained the decision right).

When answering this question, please take the following procedure into account: you (your team) can purchase the "right to roll the dice yourself" by stating your maximum willingness to pay for this right - this must lie between 1 and 30. A random decision will then determine a price between 1 and 30 for this right. If the price is less than or equal to your willingness to pay, you will pay the price and roll the dice yourself. If the price is higher, you retain the entire 30 points (per person) and the head of the study will roll the dice for you. This procedure insures that it is best for you to state how many points the value of rolling the dice yourself if worth.

${ }^{22}$ The same instruction for both roles with team treatment modifications 
Example 1: You (Your team) are (is) willing to pay a maximum of 5 points (per person) in order to be able to roll the dice yourself (your willingness to pay is 5 points). The random device determines that the price for rolling the dice yourself is 18 points. As your willingness to pay (per person) is less than the price, you do not pay the price. You retain all 30 points and the head of studies rolls the dice.

Example 2: You (Your team) are (is) willing to pay a maximum of 25 points (per person) in order to be able to roll the dice yourself (your willingness to pay is 25 points). The random device determines that the price for rolling the dice yourself is 7 points. As your willingness to pay (per person) is greater than the price, you pay the price of 7 points. You retain 23 of the 30 points and roll the dice yourself.

If you are willing to pay something to be able to roll the dice yourself, we ask you to enter your exact willingness to pay. If you (your team) delegated or did not receive the decision right in the first part of the study, you will receive the additional 30 points automatically.

If you have questions about these instructions, please raise your hand. We will then come to your desk. Otherwise click on the "continue" button. 


\section{A.5.4 Instructions - Additional}

\section{Loss aversion lotteries ${ }^{23}$}

You now have the possibility to participate in a series of lotteries. Potential earnings will be added to your overall income, potential losses will be subtracted from your overall income.

You will soon see a series of lottery decisions. The team decision works as in the previous rounds. Please decide for each lottery whether you want to "accept" or "reject" the lottery. At the end, one lottery will be randomly chosen.

If you accepted that lottery, a random process will determine whether you have won or lost the lottery. If you rejected the lottery nothing happens and your income remains unchanged.

Please decide for each of the following lotteries whether you want to accept or reject the lottery:

1. With $50 \%$ probability you win 3 Euro (per person), with $50 \%$ probability you lose 1 Euro (per person).

2. With $50 \%$ probability you win 3 Euro (per person), with $50 \%$ probability you lose 1.50 Euro (per person).

3. With $50 \%$ probability you win 3 Euro (per person), with $50 \%$ probability you lose 2 Euro (per person).

4. With $50 \%$ probability you win 3 Euro (per person), with $50 \%$ probability you lose 2.50 Euro (per person).

5. With $50 \%$ probability you win 3 Euro (per person), with $50 \%$ probability you lose 3 Euro (per person).

6. With $50 \%$ probability you win 3 Euro (per person), with $50 \%$ probability you lose 3.50 Euro (per person).

\footnotetext{
${ }^{23}$ The same instruction for both roles with team treatment modifications
} 


\section{A.5.5 Handout - Supplementary Information for the participants}

\section{Cost sheet (here: high costs)}

\section{Costs of the probability of success}

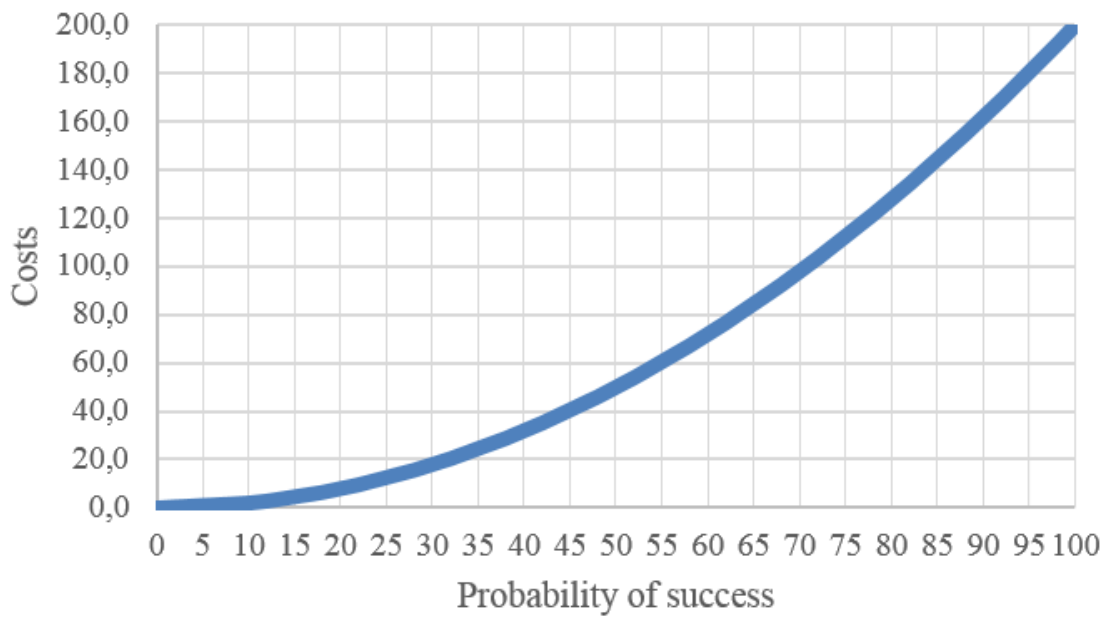

\begin{tabular}{|c|c|}
\hline \begin{tabular}{c|}
$\begin{array}{c}\text { Probability of } \\
\text { success }\end{array}$ \\
\end{tabular} & Costs \\
\hline 0 & 0,0 \\
\hline 1 & 0,2 \\
\hline 2 & 0,4 \\
\hline 3 & 0,6 \\
\hline 4 & 0,8 \\
\hline 5 & 1,0 \\
\hline 6 & 1,2 \\
\hline 7 & 1,4 \\
\hline 8 & 1,6 \\
\hline 9 & 1,8 \\
\hline 10 & 2,0 \\
\hline 11 & 2,4 \\
\hline 12 & 2,8 \\
\hline 13 & 3,4 \\
\hline 14 & 4,0 \\
\hline 15 & 4,6 \\
\hline 16 & 5,2 \\
\hline 17 & 5,8 \\
\hline 18 & 6,4 \\
\hline 19 & 7,2 \\
\hline 20 & 8,0 \\
\hline 21 & 8,8 \\
\hline 22 & 9,6 \\
\hline 23 & 10,6 \\
\hline 24 & 11,6 \\
\hline 25 & 12,6 \\
\hline
\end{tabular}

\begin{tabular}{|c|c|}
\hline \begin{tabular}{|c|}
$\begin{array}{c}\text { Probability of } \\
\text { success }\end{array}$ \\
\end{tabular} & Costs \\
\hline 26 & 13,6 \\
\hline 27 & 14,6 \\
\hline 28 & 15,6 \\
\hline 29 & 16,8 \\
\hline 30 & 18,0 \\
\hline 31 & 19,2 \\
\hline 32 & 20,4 \\
\hline 33 & 21,8 \\
\hline 34 & 23,2 \\
\hline 35 & 24,6 \\
\hline 36 & 26,0 \\
\hline 37 & 27,4 \\
\hline 38 & 28,8 \\
\hline 39 & 30,4 \\
\hline 40 & 32,0 \\
\hline 41 & 33,6 \\
\hline 42 & 35,2 \\
\hline 43 & 37,0 \\
\hline 44 & 38,8 \\
\hline 45 & 40,6 \\
\hline 46 & 42,4 \\
\hline 47 & 44,2 \\
\hline 48 & 46,0 \\
\hline 49 & 48,0 \\
\hline 50 & 50,0 \\
\hline
\end{tabular}

\begin{tabular}{|c|c|}
\hline \begin{tabular}{|c|}
$\begin{array}{c}\text { Probability of } \\
\text { success }\end{array}$ \\
\end{tabular} & Costs \\
\hline 51 & 52,0 \\
\hline 52 & 54,0 \\
\hline 53 & 56,2 \\
\hline 54 & 58,4 \\
\hline 55 & 60,6 \\
\hline 56 & 62,8 \\
\hline 57 & 65,0 \\
\hline 58 & 67,2 \\
\hline 59 & 69,6 \\
\hline 60 & 72,0 \\
\hline 61 & 74,4 \\
\hline 62 & 76,8 \\
\hline 63 & 79,4 \\
\hline 64 & 82,0 \\
\hline 65 & 84,6 \\
\hline 66 & 87,2 \\
\hline 67 & 89,8 \\
\hline 68 & 92,4 \\
\hline 69 & 95,2 \\
\hline 70 & 98,0 \\
\hline 71 & 100,8 \\
\hline 72 & 103,6 \\
\hline 73 & 106,6 \\
\hline 74 & 109,6 \\
\hline 75 & 112,6 \\
\hline
\end{tabular}

\begin{tabular}{|c|c|}
\hline $\begin{array}{c}\text { Probability } \\
\text { of success }\end{array}$ & Costs \\
\hline 76 & 115,6 \\
\hline 77 & 118,6 \\
\hline 78 & 121,6 \\
\hline 79 & 124,8 \\
\hline 80 & 128,0 \\
\hline 81 & 131,2 \\
\hline 82 & 134,4 \\
\hline 83 & 137,8 \\
\hline 84 & 141,2 \\
\hline 85 & 144,6 \\
\hline 86 & 148,0 \\
\hline 87 & 151,4 \\
\hline 88 & 154,8 \\
\hline 89 & 158,4 \\
\hline 90 & 162,0 \\
\hline 91 & 165,6 \\
\hline 92 & 169,2 \\
\hline 93 & 173,0 \\
\hline 94 & 176,8 \\
\hline 95 & 180,6 \\
\hline 96 & 184,4 \\
\hline 97 & 188,2 \\
\hline 98 & 192,0 \\
\hline 99 & 196,0 \\
\hline 100 & 200,0 \\
\hline
\end{tabular}

